\title{
DEFYING THE LAWS OF NATURE?: MENSTRUATION AND FEMALE INTELLECT IN HISTORICAL PERSPECTIVE
}

\author{
AMANDA L. JENKINS \\ A THESIS SUBMITTED TO \\ THE FACULTY OF GRADUATE STUDIES \\ IN PARTIAL FULFILLMENT OF THE REQUIREMENTS \\ FOR THE DEGREE OF \\ MASTER OF ARTS
}
GRADUATE PROGRAM IN PSYCHOLOGY YORK UNIVERSITY, TORONTO, ONTARIO

AUGUST 2014

(C) AMANDA L. JENKINS, 2014 


\begin{abstract}
In 19th and early 20th century America menstruation began to be constructed as a barrier to women wishing to access higher education. Male physicians warned of the supposed dangers studying would impose upon female reproductive systems. A closer look at these perspectives are explored in greater depth through my research question "What discourses has science constructed around the relationship between menstruation and female cognitive ability from the late 1800s to today in America?" This paper explores two key figures in the battle against educating women: Edward H. Clarke (18201877) and G. Stanley Hall (1844-1924). Despite substantial support for Clarke and Hall's arguments, many feminists sought to disprove their theories. Psychologist Leta Hollingworth, and physicians Clelia Mosher and Mary Putnam Jacobi were forerunners in these arguments. A look at how and why menstrual invalidism has persevered from 19th century to today will be explored through Nancy Tuana's epistemology of ignorance framework.
\end{abstract}


This thesis is dedicated to my parents. 


\section{ACKNOWLEDGEMENTS}

This project would not have been possible without the support of many people. Many thanks to my advisor, Alex Rutherford, who read numerous revisions of this paper and to my committee member Mike Pettit for his thoughtful comments and suggestions. I would also like to thank my parents, my sister Natasha and Jeff for their unconditional support, and my friends Jennifer, Lan and Stephanie whose support and encouragement was also deeply appreciated. 


\section{TABLE OF CONTENTS}

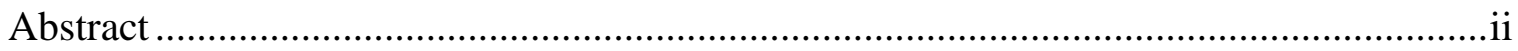

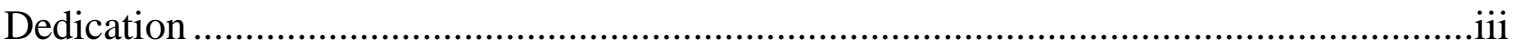

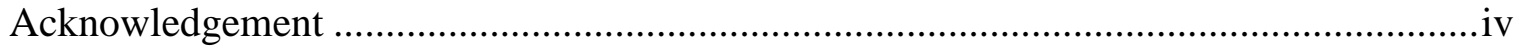

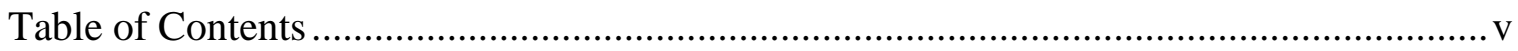

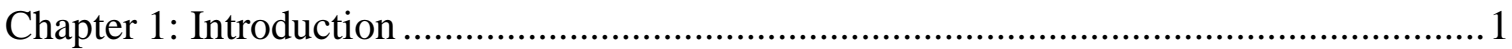

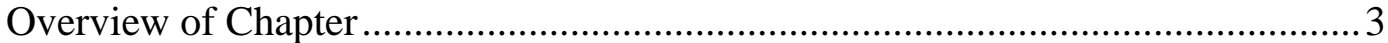

Epistemology of Ignorance Framework............................................................. 4

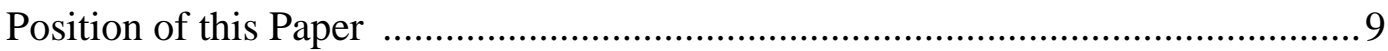

Chapter 2: Historical Views of Menstruation in Western History ......................................10

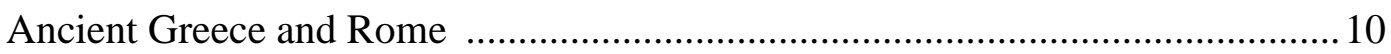

Medieval Western Europe ……………………………...................................15

Early Modern Western Europe ......................................................................19

19th Century United States, Canada and England .................................................24

20th Century United States, Canada and England ..............................................2

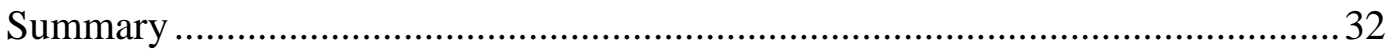

Chapter 3: Menstruation and Denial to Higher Education ..................................................34

Clarke, Education and Women's Physiology ………............................................35

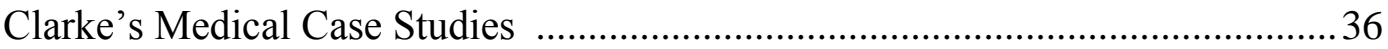

Clarke's Medical Advice and Proposed Intervention ............................................39

G. Stanley Hall and Women's Higher Education ...............................................46

G. Stanley Hall and the Variability Hypothesis ................................................50

Women's Education: A Separate Sphere ………………………………......52

Supporters of Clarke and G. Stanley Hall .......................................................57

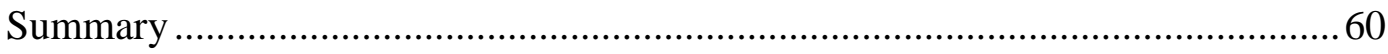

Chapter 4: Feminist Responses to Clarke, Hall and Female Invalidism ...........................64

Feminism and Medicine: Mary Putnam Jacobi and Clelia Duel Mosher ..............65 
Feminist Activism: Julia Ward Howe's Response to Clarke...............................72

Psychologist Leta Stetter Hollingworth: Functional Periodicity and the Variability

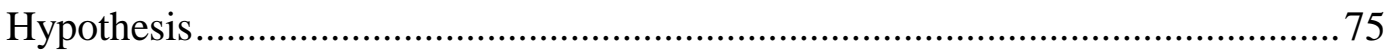

A New Definition of Femininity: The New Woman ..........................................8 80

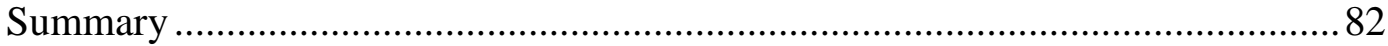

Chapter 5: Mid-20th Century to Modern Day Interpretations of the Menstrual Invalidism

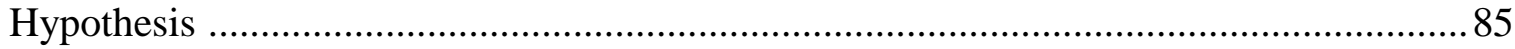

WWII, Menstrual Invalidism and the Female Workforce ..................................86

Postwar: Medicalization of Menstruation ...........................................................94

Second Wave Feminism and The Women's Health Movement ......................... 101

Menstruation and Third Wave Feminism ..................................................... 105

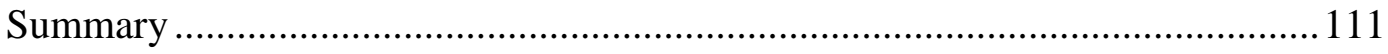

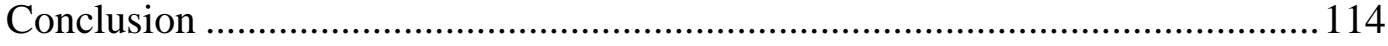

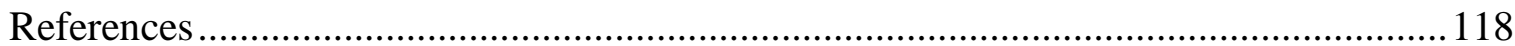




\section{Chapter 1: Introduction}

A girl cannot spend more than four, or, in occasional instances, five hours of force daily upon her studies, and leave sufficient margin for the general physical growth that she must make....If she puts as much force into her brain education as a boy, the brain or the special apparatus (i.e., the reproductive system) will suffer. (Clarke, 1873, p.156-157)

The psychologist writes that there are grave and profound changes in mind and body during menstruation; yet he makes no allowance for this in his experiments on women subjects. The physician declared fifty years ago that women were forever unfitted for higher education because of this function; yet the number of women graduated from colleges and universities in perfectly normal health increases yearly. It is positively asserted that women cannot successfully pursue professional and industrial life because they are incapacitated, and should rest for one-fifth of their time; yet it is not proposed that mothers, housekeepers, cooks, scrubwomen and dancers should be relived periodically from their labors and responsibilities.

(Hollingworth, 1914, p.97)

The effect of menstruation on women's capacity for higher education and intellectual accomplishment has been a contentious subject since the 19th century. The root of this contention originally revolved around social and scientific beliefs that overstressing a woman's brain could lead to reproductive damage. ${ }^{1}$ This reasoning was used to exclude women from many male-dominated spheres, and both psychological and medical professionals used their scientific authority to advance these beliefs and practices. However, their authority was not uncontested. This contestation is reflected in the above quotes outlining medical and feminist views. Physician Edward Clarke epitomized 19th century medical thought on menstruation. Like Clarke (1873), many male physicians argued that the education of women would result in the weakening of women's ability to reproduce, as studying would consume the blood and energy required for menstruation. Recommendations for women to restrict studying and instead rest their bodies and minds were widespread in America and overseas. However, these arguments were based on little to no empirical evidence and were challenged by feminists. Feminist

\footnotetext{
${ }^{1}$ A more contemporary manifestation of this belief would be that women become crazy or irrational during menstruation, and thus unfit for certain kinds of work. See Chapter 5.
} 
empiricists, such as psychologist Leta Hollingworth, were quick to undermine biased studies conducted by male psychologists and physicians. As expressed in Hollingworth's sentiments above, women who were advised rest were those who defied traditional gender roles. Menstruation, then, was used to maintain traditional gender roles by curtailing the educational aspirations of women (Bullough \& Vough, 1973, Rosenberg, 1982). Despite opposing arguments, Clarke and Hollingworth both used science as a medium to elevate their claims.

These arguments inform my research question, "What discourses has science constructed around the relationship between menstruation and female cognitive ability from the late 1800s to today?" I will be exploring how female intellect and the association with menstruation has been analyzed from medical, psychological and feminist perspectives during this era. Understanding the association between menstruation and perceived female intellectual inferiority establishes a platform from which to explore the systematic oppression of women. Medical and psychological discourses around menstruation have also informed how roles assigned to females have been understood across societies and historical periods. This association might also reveal how a physiological process such as menstruation has traversed psychological, medical and academic spheres in late 19th and early 20th century America. I will also be exploring how the menstrual invalidism hypothesis has been transformed since this time and how it has influenced discourses around the modern day medicalization of menstruation. Examining the intersection of gender, education and menstruation as a framework of 
analysis may reveal new understandings of how a normal process became a deficit and vulnerability for women throughout the 19th and 20th century.

Overview of Chapters

In my first chapter, I review and summarize historical views on menstruation generally, with a focus on these views in the Western context. This review reveals a variety of discourses where menstruation has been viewed both positively and negatively. A review of historical attitudes towards menstruation is essential in providing the context for how menstruation was influenced and portrayed in late 19th and 20th century America, which is the main focus of this thesis. Attitudes dating back to Ancient Greece and Rome continue to inform theories that claim women's bodies are inferior to men. The historical rationale for this claim is linked to menstruation, especially in western history where such taboos have existed since antiquity.

Upon this historical template I narrow my analysis in chapters 3 and 4 to examine scientific discourses around menstruation as they began to be constructed by medical and psychological professionals by the end of the 19th century. Specifically, I focus on the prominent debate between male physicians and psychologists and their feminist colleagues over the impact of menstruation on women's suitability for higher education. Prominent men in this discussion include physician Edward Clarke and psychologist G. Stanley Hall. These discourses infiltrated pedagogy and public policy, resulting in women accessing higher education and influencing how female bodies and knowledge have been represented in the traditionally male dominated fields of medicine and psychology. However, many eminent feminist activists including Leta Hollingworth, Mary Putnam 
Jacobi, Clelia Mosher, and Julia Howe challenged theories that menstruation hindered them physically and intellectually. They worked during the Progressive Era, a period in America that saw women seeking greater rights and gender equality inside and outside the home. Historical newspapers from the 19th and early 20th century obtained from the Library of Congress Chronicling America, American Memory Project and ProQuest online databases will be used to explore public responses to Hall, Clarke and the above feminists.

Finally, I examine the emergence of premenstrual tension, PMS, PMDD as midlate 20th century versions of the menstrual invalidism hypothesis, and examine how feminist scientists combatted these beliefs, in contrast to their earlier century feminist forebears. An exploration of feminist movements including the women's health movement and second and third wave feminism and their use of embodied knowledge to discount medical discourse will be introduced. An analysis of how feminists in the 19th century utilized different methods in challenging menstrual invalidism in comparison to 20th century feminists will be presented.

\section{Epistemology of Ignorance Framework}

In this thesis I will be exploring how the perseverance of beliefs in menstrual invalidism from the late 19th century to today enabled male medical and psychological discourses to preserve traditional gender roles by discounting feminist epistemologies through the production of ignorance. The epistemology of ignorance, which will be framing my thesis, is described by Tuana (2008) as our ability to "understand the practices that account for not knowing, that is, for our lack of knowledge about a 
phenomena or, in some cases, an account of the practices that resulted in a group unlearning what was once a realm of knowledge" (p.108). Tuana discusses the diverse ways of 'not knowing' in her taxonomy of ignorance. Her taxonomy includes six ways of how ignorance has been sustained and constructed. In Tuana's first category of ignorance, knowing that we do not know, but not caring to know, knowledge is pursued in the interest of dominant groups. Certain questions or knowledges deemed unimportant are ignored by these groups who do not inquire further. Decisions by those who hold power privilege certain knowledges while oppressing others. Pharmaceutical companies deciding not to research male hormonal contraceptives on the basis of being unprofitable is one example of this ignorance.

In the second type of ignorance, we do not even know that we do not know, we fail to recognize our internal bias or lack of awareness of certain topics because "our current interests, beliefs, and theories obscure them" (Tuana, 2006, p.6). Awareness of this ignorance results in the decision to either pursue what is unknown or simply continue to ignore as a result of not caring. This type of ignorance is identified by Tuana as involving sexist or androcentric biases when it pertains to women's bodies. For example, 20th century medicine used the male body as the normative body, ignoring the clitoris in female anatomy illustrations. The division of males into the category of 'external genitalia' and females into 'internal genitalia' prevented physicians from acquiring anatomical knowledge on the clitoris and labia which were viewed as being external and unassociated with reproduction. 
In the third type of ignorance, they do not want us to know, one is actively discouraged from knowing. This is produced by those in power who have access to knowledge kept hidden from selective groups. Often this knowledge is kept secret as a means of producing profit. Tuana provides the example of withholding health implications of certain products such as tobacco or the birth control pill for the purposes of profit. Companies who withheld information about these side effects produced and sustained public ignorance to protect their finances.

Tuana's fourth category, willful ignorance, is ignorance that is actively produced and maintained over time. This ignorance is in the interests of certain individuals or groups who choose to be ignorant. Tuana (2006) adds that willful ignorance can be "a belief we know to be false but insist on repeating" which produces "a systematic process of self-depletion, a willful embrace of ignorance that infects those who are in positions of privilege, an active ignoring of the oppression of other and one's role in that exploitation" (p.11). This form of ignorance is often linked to oppression and racism. Privileged groups produce this oppression by ignoring the histories and narratives of individuals who are deemed to be inferior. This has been demonstrated by the women's health collective in the 1960's who ignored the topic of incest in the early editions of Our Bodies, Ourselves. Despite the high rates of incest that occurred in America, reported to be as high as 50 percent, many health practitioners denied the existence of the issue.

In the fifth category of ignorance, ignorance produced by the construction of epistemically disadvantaged identities, knowledge constructed by individuals or groups who are deemed as 'non knowers' are ignored. These individuals and groups are viewed 
as untrustworthy and produce knowledge judged not to be credible. Feminist epistemologies and minorities have often been the targets of this ignorance. This has included indigenous groups whose practices and aspects of their knowledge have been discredited by colonial groups.

The final category of ignorance, loving ignorance, differs from Tuana's previous categories of ignorance which focuses on the practices of exclusion and oppression. Instead, loving ignorance, is accepting knowledge that we cannot know by acknowledging the limits and capacities of our knowledge. Understanding the areas of knowledge and certain experiences that we cannot know and the reasons why are part of this loving ignorance. This category of ignorance has been applied to the women's health movement who raised issues of class and race by embracing the experiences of both white women and women of colour. Experiences of these women were understood to be experiences that could not always be shared.

Similar to knowledge then, ignorance is often constructed and actively preserved by those in power. As a result, ignorance can be used to marginalize and oppress knowledge that circulates outside of dominant groups. Additionally, the active process of making certain knowledge invisible oppresses groups that have been epistemically disadvantaged. Tuana points out that historically this oppression has been against women's bodies. Male scientists have supported this oppression by using science to reinforce 'facts' about women's bodies that have little to no validity. Instead, these scientific 'facts' are influenced by social and cultural biases that reinforce gender 
differences. The production of knowledge and/or ignorance serves as a way to privilege or disadvantage certain groups.

I have applied Tuana's epistemology of ignorance to the persistence of the menstrual invalidism hypothesis in the following ways. In chapters 3 and 4, Tuana's fourth category of ignorance, willful ignorance, will be applied to male physicians and psychologists who declared that women were unfit for higher education due to menstruation even when it was documented that the number of women who graduated from college and university increased yearly (Hollingworth 1914). Additionally, Tuana's fifth category of ignorance, ignorance produced by the construction of epistemically disadvantaged identities will highlight the ignorance by Clarke and Hall of feminists who they constructed as 'non knowers'.

In chapter 5, Tuana's fourth category of ignorance, willful ignorance, will be extended to the medical and psychological institutions as well as the American government and military's ignorance of studies that disproved menstrual disabilities. Tuan's second category of ignorance, we do not even know that we do not know, will be applied to cultural biases that ignored the idea of menstruation being viewed in a positive light. The third category of ignorance, they do not want us to know, will be used to analyze how growing pharmaceutical companies in the 20th century hid knowledge around birth control side effects from women as a way to produce profit.

In applying Tuana's epistemology of ignorance to the persistence of the menstrual invalidism hypothesis in medical and psychological research, I suggest that male physicians, physiologists, and medical institutions have consistently ignored knowledge 
that disproves menstrual invalidism, despite the challenges of feminist scientists. Reasons for why menstrual invalidism has persisted will be further explored throughout the thesis. These include the preservation of gender roles, reinforcing female inferiority, and corporate profit.

\section{Position of this Paper}

In this project I use scientific discourses to understand how menstrual invalidism has persevered since the 19th century by assuming new forms. By situating the different forms menstrual invalidism has taken within a scientific, historical and cultural context, I explore how these discourses have impacted women's bodies. In the existing literature, feminists have explored how women's bodies have been portrayed by science. In The Egg and the Sperm, Emily Martin (1991) examines how culture informs scientists' descriptions about the natural world. These cultural assumptions are often based upon definitions of male and female stereotypes depicting female biological processes as inferior to male processes. These hidden assumptions in science imply that women are naturally inferior to men.

My position reflects that of Martin's (1991) stance on how women's bodies have been portrayed by science. However, I am extending this position by demonstrating how science has also been used by women to deconstruct these negative cultural assumptions about the female body. I am extending the literature on how women's bodies have been portrayed by science by applying Tuana's taxonomy of ignorance to late 19th and early 20th century scientific discourses. Tuana's framework offers a critical lens for understanding menstrual invalidism and the forms it has taken since the 19th century. 
Chapter 2: Historical views of menstruation in Western history

Menstruation has been viewed from multiple perspectives throughout history. These perspectives offer insight into how cultures have perceived menstruation through the lenses of medicine, religion, and gender. If there is one pattern to be discerned, it is the existence of conflicting views straddling positive and negative attitudes towards menstruation. To set up a focused study of late 19th century and early 20 th century debates about menstrual invalidism, this chapter begins by providing a broad historical overview of menstruation with a focus on Western historiography. The overview acknowledges perspectives of menstruation beginning with Ancient Greece and Rome, extending to Medieval Europe, Early Modern Europe, $19^{\text {th }}$ and 20th century England, and ending with North America. The introduction of menstrual products and premenstrual syndrome in North America during the 19th and 20th century suggests another dynamic at play in how menstruation has been portrayed. Lastly, throughout the chapter I will be exploring how theories of menstruation have shaped gender roles and have generally constrained women's roles to the domestic sphere.

\section{Ancient Greece and Rome}

Discourses about menstruation in the Western world can be traced back to Ancient Greece. Historian Sara Read explored Ancient Greek myths cloaking menstruation by retelling a story by Greek philosopher Hypatia who threw menstrual cloths at an unwanted suitor in an attempt to dampen his idealization of the romanticized female body (Read, 2008). Revisions of this story emerged again during the eighteenth century when handkerchiefs replaced menstrual cloths that still targeted unwanted suitors (Crowder, 
1766). The change in item was believed to be made by some men who viewed Hypatia as a woman of virtue and wanted the story to be aligned with their vision of refinement and delicacy (Crowder, 1766). Examples of this vision are evidenced in Memoirs of Eminent Ladies by Crowder (1766) who described Hypatia as a "miracle of virtue and prudence", and a "lady of beauty, modesty, wisdom and virtue" (p.35, 36). Yet another revision of the story omitted the throwing of menstrual cloths completely (Lewis, 1721).The story of Hypatia represents one example of how menstruation was referenced in Greek myths. However, historian Robert Parker (1983) notes that references to menstruation in Ancient Greece were mainly in medical literature. Even in Old Comedy, menstruation was not alluded to, unlike other bodily functions. Parker (1983) argues that this lack of reference may signify taboos that existed around menstruation.

In reflecting upon the original story and later revisions, several interesting perspectives on menstruation are revealed and appear to have informed contemporary views on menstruation. The original story of Hypatia placed menstruation as a female bodily process that separated the idealized and actual female body. Read (2008) argues that the story of Hypatia plays upon the ancient belief that a man who was exposed to a women's menstrual blood would be cured of love sickness. This associates meanings to menstruation as a fluid that is noxious and repugnant. This view may have been restored in the 18th century tale cautioning woman of virtue against being associated with menstruation or menstrual blood. The final revision expunges this section of the story perhaps in an effort to conceal any mention of menstruation. This may be further 
evidenced by the English translations of the story where words linked to menstruation or sexuality were not translated from Latin (Read, 2008).

Greek philosopher Aristotle provides another avenue of how menstruation was viewed. As Bildhauer (2005) has shown, his philosophical ideas about menstruation influenced medical ideas around reproduction as well as gender roles. I will now more fully describe the intersection of Greek philosophy and gender roles in regards to menstruation. Aristotle believed that sperm and menstrual blood belonged to the same category of bodily fluids but represented different aspects of the soul in men's and women's bodies (Delaney, Lupton, \& Toth, 1976). Menstrual blood was seen as having little contribution to an unborn child and only contributed the reproductive and nutritive part of the soul while sperm contributed all other aspects of the soul, including the rational soul (Hiltmann, 2005). The female, according to Aristotle, only provided the material while the male "provides that which fashions the material into shape; this, in our view, is the specific characteristic of each of the sexes: that is what it means to be male or to be female" (as cited in Delaney et al. p.248). This quote by Aristotle represents a dichotomy between males as the active partner and females as the passive body (Delaney et al., 1976). Women themselves were considered deformed males which resulted from the female embryo unsuccessfully forming fully into a male embryo (Bildhauer, 2006). Additionally, the lower value placed on the contribution of menstrual blood to a foetus also resulted in Aristotle arguing that women were inferior to men since men contributed the more valued material (Vertinsky, 1990). 
Views of menstruation in Ancient Rome were highly influenced by previous Greek regulations and practices governing menstruation. Pliny the Elder's Natural History is one example of Roman attitudes toward menstruation which is described as polluting, dangerous and powerful (Parker, 1983). This view was similar to Greek perceptions of menstruation. For example, Greek physician Soranus described menstrual blood as a natural catharsis of the body that only proved to be dangerous when the process stopped (Lennon, 2010). Other theories about menstruation were written centuries later by Macrobius in The Saturnalia which describes menstrual blood as an impure substance that needed to be purged from the body (Lennon, 2010). The danger resulting from being in contact with menstrual blood was described in multiple forms. Sexual contact was one form that resulted in contamination. Even speaking of these acts were seen as impure and shameful (Richlin, 1992). Other forms of contamination through menstruation included agriculture and farming. L. Iunius Columella warns others of a menstruating women's touch in his writings On Agriculture. He states that menstruating women should not be near crops of gourds or cucumbers, "for often the growth of plants is wilted by the contact of women. Indeed, if she is menstruating, the new crops will be killed even by her glance" (as cited in Lennon, 2010, pp.75). Columella advised farmers who were having pest problems to have a girl who just started menstruating to walk around the farmer's fields three times bare footed. This would result in the death of all insects that infected the fields. These descriptions of menstruation reveal a negative perception of menstruation as something that is impure and polluting. Alternatively, Warde-Fowler (1911) has argued that in fact descriptions such as Columellas highlights 
positive aspects of this menstrual taboo. The power associated with menstruation provided a beneficial outcome in riding crops of insects. However, Lennon (2010) points out that menstrual blood only proved useful when strictly controlled and still questions the positive facets in writings such as Columella and Pliny the Elder.

Pliny the Elder wrote extensively on menstruation and his influence went beyond the borders of Ancient Rome. Pliny believed the effect of menstrual blood could be powerful enough to kill bees and crops, rust bronze and iron, turn dogs insane, spoil fruit, or even cause women and mares to miscarry. Pliny also noted that men who had sexual intercourse with a menstruating woman during lunar or solar eclipse were susceptible to disease or death (Parker, 1983). However, despite the harmful properties of menstruation noted, Pliny also saw the power of menstrual blood as beneficial. Pliny argued that the touch of a menstruating woman could cure skin growths, rabid dog bites and fevers among others. Menstrual blood was even ascribed magical properties by Pliny who believed it could ward off evil spirits and demons, used as an offering to a god or even as a love charm (Delaney et al. 1976). Menstrual blood in this way was seen as enveloping supernatural qualities that could heal as well as protect (Lennon, 2010).

Despite the Roman literature that describes menstruation as polluting or dangerous, this was not associated with religious sites. According to Lennon (2010), there were no writings on women or men who may have come into contact with menstrual blood being excluded from religious ceremonies or sites. This is quite different from Medieval and Elizabethan England where a shift in how menstruation is viewed prevents menstruating women from entering religious temples. 


\section{Medieval Western Europe}

Ancient Greek and Roman ideas also infiltrated the menstrual discourses of Medieval Western Europe. Theories of menstruation by Hippocrates and Galen, such as the Galenic humoral theory, influenced how physicians approached women's bodies and menstruation (Read, 2008). Hippocrates' theory, which stated that women menstruated in order to purge their bodies of impurities, was revered during seventeenth century England (Crawford, 1981). Galen professed himself the successor of Hippocratic ideology and continued Hippocrates' legacy in medicine and his specialty in women's diseases (McClive, 2004).

The Galenic humoral theory provided some positive views of menstruation. The theory argued that there were four humors in the body including black bile, yellow bile, phlegm and pure blood. Blood was believed to be the most vital of all humors and was the basis for the elements of the body including menstruation (Bildhauer, 2005). Imbalance of these four humors could cause disease or disorders requiring a phlebotomy or bloodletting which would restore the harmony of the humors. Galen stated that menstruation was a natural form of phlebotomy for women resulting in women being less prone to spasm, lethargy and melancholy (Hindson, 2009). However, this more positive Galenic view clashed with the more negative Hippocratic theory of menstruation. The result was multiple beliefs around menstruation rather than a single all-encompassing belief. Phlebotomy of menstrual blood during menstruation was viewed through both a positive and negative lens. As an example, menstruation was seen as harmful if it was not removed from the body or became harmful in excessive quantity or in too little quantity 
(Crawford, 1981). These views may represent ideas during Elizabethan England that menstruation in moderate quantity was necessary for a healthy body. Anything that deviated from a moderate degree of menstrual blood may have been viewed as needing intervention or medical treatment. However, what was described as moderate was defined by physicians and medical experts who were typically male. This role of the expert in defining what is normal in women's health is a theme apparent throughout history and is still visible today.

Other beliefs carried from Ancient Greece and Rome included those of Pliny the Elder and Isidore of Seville who described menstrual blood as dangerous and poisonous in De secreta mulierum (Secrets of Women) (Read, 2008). This medical text was translated from Latin to German in the 15th century and greatly influenced Western Medieval European thought (Bilhauer, 2006). The 'secrets' of women discussed in these texts pertain mainly to menstruation and the idea that it must be concealed from men. Part of this concealment resulted from accusations that menstruation was polluting and dangerous to men and babies. This belief highlights one strand of medieval thought that distinguished between menstruating and non-menstruating bodies (Bildhauer, 2005).

Bildhauer (2005) has argued that the concept of menstruation as a secret functioned to create a gender distinction that has excluded women from scholarly discourse. Although the subjects of De secreta mulierum are women, the text is written by a male author to a male audience whom he invites to provide further commentaries. The text was exclusive to an elite group of men who exchanged medical ideas about women's bodies while excluding women from contributing knowledge about their own bodies, 
highlighted by the difference in number of references. Out of 119 references provided by male medical and philosophical experts, only one reference is acknowledged by 'several women' who are unnamed. Bildhauer (2006) adds that the descriptions of women in the text treats them as objects and even uses hostile descriptions, reducing women's bodies solely to their reproductive capabilities. De secreta mulierum highlights a dichotomy between men being associated with abstract knowledge that transcends the body while women were reduced to the physical body. Women's knowledge was disregarded even when it came to their own bodies. Discussion about menstruation was therefore transmitted orally between women instead of in writing which perpetuated the secrecy surrounding menstruation from men (Bildhauer, 2006).

Judeo-Christian beliefs also reveal strong negative perceptions of menstruation in Medieval Europe. Leviticus 15 states in the bible "if a woman have an issue of her blood ...she shall be unclean" and "if any man lie with her at all, and her flowers be upon him, he shall be unclean" (Geneva Bible, Leviticus 15: 19-25 English Version Translation). Some Christian authorities even debated whether Leviticus's writings were a legitimate reason to keep women out of religious institutions (Green, 2005). This was similarly expressed by Theodore Bishop of Canterbury in the seventh century when he banned menstruating women from entering the church or taking holy communion, as they were deemed to be contaminating (Mulvey-Roberts, 2005). Leviticus 15's verses highlight the evolving taboo surrounding menstruation during Medieval England and France where an emphasis was placed on the impurity of menstrual blood (McClive, 2004). However, even more polluting and impure than menstrual blood was blood shed during childbirth. 
Women who had recently given birth were required to undergo a ritual cleansing before entering a church (Mulvey-Roberts, 2005). This purification was not always accepted however. Pope Innocent III in 1199 disallowed any woman in France who had recently given birth from entering the church (Ranke-Heinemann, 1990).

Hindson (2009) argues that not all views of menstruation were negative during this period in England. She states that although De secreta mulierum was popular during Elizabethan England, this did not indicate full acceptance of Plinian and Isiodorian ideas and in fact many of these ideas were rejected during this time. McClive (2004) posits that Pliny the Elder also advocated positive and therapeutic benefits of menstruation including curing tumors and fevers; however these are less cited. Other ideas that were not fully accepted were negative Christian beliefs such as Leviticus 15 which were largely rejected by the mass population. In fact, Christianity espoused more positive beliefs around menstruation than other religions during this period such as Judaism in England (Hindson, 2009). In a similar vein, O'Grady (2003) argues that historians have been misinterpreting Leviticus 15 's verses. She states that Leviticus 15 was concerned with overall cleanliness and hygiene and was not associating menstruating women with sinfulness. In fact, O'Grady (2003) continues to state that the biblical text includes reference to both male and female pollution and is not exclusive to female menstruation.

Menstruation therefore has been viewed from various perspectives. Hindson (2009) proclaims that a single static model, either solely negative or positive, is not sufficient in describing historical views of menstruation. She instead argues for a more dynamic approach that describes fluctuating views of menstruation and menstrual blood 
based upon changing historical circumstances. Historian Green (2005) has also shown that attitudes towards menstruation in Medieval Europe lay along a spectrum. This spectrum consisted of positive euphemisms such as 'flowers' to describe menstruation in medical texts to the opposite extreme where menstruation was seen as poisonous, contaminating and foul. The numerous positive and negative terms to describe menstruation and changing attitudes during Medieval England were dependent upon "the circumstances when it flowed and the health and condition of the body in which it flowed" (Hindson, 2009, p.90).

A significant historiographic issue is that the majority of references used are from male perspectives (Crawford, 1981, Hindson, 2009, Bildhauer, 2005). The majority of historical sources were written by the literate male population resulting in many female voices unrecorded (Crawford, 1981). As evidenced previously by De secreta mulierum, the outcome being women excluded from scholarly discourse even when it pertains to their own bodies (Bildhauer, 2005). The majority of female experiences of menstruation have been recorded by male physicians in their case histories however there has been some experiences written by women in private diaries (Hindson, 2009). Similarly, female authored medical texts in early modern France were quite rare (McClive, 2005).

\section{Early Modern Western Europe}

Similar to Medieval and Elizabethan England, attitudes towards menstruation in early modern France were dependent upon the conditions and the circumstances of the body during menstruation (McClive, 2005). These attitudes were also shaped by popular theories around human anatomy. For example, Thomas Laqueur (1990) argues that a one- 
sex model existed that was highly influential in early modern France as well as other European countries until the $17^{\text {th }}$ century when a shift occurred to the two-sex model. Laqueur (1990) states that the lack of terminology for female genitalia compared to male genitalia provided evidence for this one sex-model where women and men were seen as anatomically homogenous. Woman's genitalia was viewed as mirrored inversions of male. Therefore, distinctions between women and men were based on gendered or cultural differences as opposed to anatomical differences (McClive 2004). This resulted in women's bodies being viewed as incomplete male bodies and menstruation as a bodily process that could be experienced by both men and women.

Male menstrual bleeding was an interesting notion in Medieval Western Europe and continued to early modern France. This notion came from the idea that food was digested and processed into blood which then formed into other bodily fluids such as semen (Bildhauer, 2006). Bleeding haemorrhoids in men was believed to be a release of fluid and was considered healthy for the body (Green, 2005). Just as menstruation was seen as a natural way to release excess humors, haemorrhoid bleeding was seen as a parallel process in men. Some men were prone to the same accumulation of impure or poisonous matter in their bodies as were women and haemorrhoids provided a natural release (Stolberg, 2005). The periodicity of this bleeding in women and men were also seen as similarly occurring at a monthly rate (Green, 2005). Many practitioners until the eighteenth century described male bleeding in terms typically used for female menstruation (Lord, 1999). However, female and male bleeding were perceived differently in early modern medicine. Women's bodies were viewed as naturally moister 
and cooler than men's, with a weaker innate heat. The fact that women required menstruation as opposed to men where menstruation was not compulsory resulted in a pathological view of menstruation as it deviated from the 'standard male body' (Stolberg, 2005).

Biblical texts disseminated negative views of menstruation and women's bodies during early modern France. These views extended from Medieval Europe where Christianity, Judaism and Islam condemned sex during menstruation as it was viewed as unclean (Green, 2005). Sex during menstruation was seen as immoral and impure during early modern France with consequences of exile or even death (O'Grady, 2003). This may have also stemmed from views of early modern medicine where menstrual blood was deemed impure and poisonous and accumulated in the female body (Stolberg, 2005). Men who had sexual contact with a menstruating woman were seen as harming their spiritual health by breaking sacred beliefs. Even the presence of a menstruating woman was believed to cause infertility and abortion (Stolberg, 2005). Men who had sex with a menstruating woman were seen as immoral as this was determined the least likely time to conceive and produce a healthy infant (McClive, 2004). Individuals who violated this would be vulnerable to birth defects such as monstrous births (Brundage, 1987, RankeHeinemann, 1990). Early Church priests threatened that such children may be malformed, hunchbacked, feebleminded or born with one eye (Mulvey-Roberts, 2005).

Although many religions held many negative views of menstruation, some French physicians in early modern France dismissed these menstrual taboos and conceptions that women were immoral and impure. For example, physician Jacques Duval (1555-1620) 
addressed biblical taboos and argued that menstruation was a natural process, devoid of pathological associations (McClive, 2004). Jean Palfyn (1650-1730) who served as professor of surgery and anatomy in Ghent, expressed similar beliefs of the benefits of menstruation while debunking negative menstrual views.

Between 1750 and 1760, enlightened knowledge on human anatomy led to a paradigm shift in how female and male bodies were viewed, resulting in widespread abandonment of the one sex model. Some historians also argue this cognitive shift was widespread in Europe including Germany, England and Italy (McClive, 2004). Women's bodies were no longer seen as incomplete inversions of male bodies. Instead menstruation was tied solely to women's bodies and their reproductive ability thus becoming a signifier of female gender and reproduction (Lord, 1999). Menstruation was also seen as being exclusive to females which ruled out previous beliefs of male menstrual bleeding. However it was only until 1791 when the term menstruation was first documented in a French medical textbook and not until 1932 when the term was included in French dictionaries (McClive, 2004). Although the link between menstruation and female bodies was clear, the link between menstrual bleeding and pregnancy was ambiguous and undermined the previous gendered distinctions (Lord, 1999).

Similar beliefs around menstruation were held in Early Modern England. Menstruation was seen as an essential bodily function for women's health although it was still viewed as a disease (Read, 2008). However, cessation of menstruation was also classified as a disease that physicians in Early Modern England attempted to cure (Read, 2008). This cessation was deemed extremely dangerous as it was believed that this 
impure blood would either run to a woman's brain or harden into a growth (Wiesner, 1993). This belief persisted into the 19th century with physicians warning women that menstrual obstruction could result in excess blood flowing to the brain causing psychological breakdown (Shuttleworth, 1990). Similar beliefs existed in early modern Italy, where blocked menstrual blood was believed by physician Nicolo Serpetro to reroute to places such as the ears, eyes, navel, fingers, breasts and through vomiting (Katz, 1999).

Galen's humoral theory and Pliny's writings on menstruation from antiquity still circulated as explanations for the causes of menstruation. Cultural and religious taboos around menstruation as well as prejudice contributed to a lack of discussion around menstruation during this period. Protestant religion and the Geneva bible played a significant part in this taboo by encouraging women to self-examine as part of a healthy lifestyle (Read, 2008). Descriptions of menstruation in the Geneva bible portrayed menstrual blood in a negative light as being unclean, filthy, shameful, and linked to disease which may have added to the secrecy around menstruation (Read, 2008). Similarly, Hebrew scripture portrayed menstruating women as ritually and physically impure and should be avoided by others (Wiesner, 1993). During the early modern period, this taboo was altered in Jewish communities, where avoidance was contained to only between a husband and wife during menstruation. Other religions during the early modern period such as the Orthodox Slavs in Eastern Europe prohibited menstruating women from taking communion or entering a church (Wiesner, 1993). 
The negative menstrual descriptions and beliefs in Early Modern Europe may have contributed to secrecy around menstruation. Read (2008) argues that this secrecy led to limited resources available to early modern women in how to manage menstrual blood loss. Lack of discussion around sanitary measures for menstruation may also suggest menstrual taboos of shame or embarrassment (Read, 2008). Some evidence reveals that women consulted other women and midwives for menstrual ailments (Wiesner, 1993).

\section{9th Century United States, Canada and England}

The theories of Hippocrates and Aristotle regarding menstruation were still highly discussed by American physicians during the 19th century (Bullough \& Voght, 1973). Menstrual myths, such as the belief that menstruation was controlled by the moon, continued to circulate within the medical community. Experimental work beginning in the 1890 's on human hormones led to greater understanding on how menstruation functioned. However, many American physicians remained unsure of the role that the uterus, ovaries and fallopian tubes played in menstruation (Bullough \& Voght, 1973). This lack of understanding about the female body led to perpetuating and reinforcing taboos and negative beliefs about menstruation (Fingerson, 2009). This misunderstanding led to restrictions around women attending higher education for fear that it would affect reproductive capabilities. Some physicians such as Alexander Skene believed that bodies had a limited amount of energy (Mitchinson, 1991). He stated that women must conserve this energy for reproductive capabilities for fear that general stress on the body affected their mental growth that decreased over time (Mitchinson, 1991). These beliefs were strongly held by many prominent physicians in America as well as Europe who 
adamantly discouraged women from achieving higher education (a point that will be discussed further in subsequent chapters).

In Canada during the 19th century, menstruation was viewed as an illness that needed to be treated. Lack of menstrual blood was indication of illness during the 19th century, similar to theories that existed during the medieval ages (Martin, 1994). Many Victorian physicians believed women were not able to carry the stress of menstruation without suffering from ill health. Young women were advised to avoid pregnancy until the age of twenty, from wearing tight fitted clothing and engaging in exercise that was geared towards boys in they wanted to prevent illness (Mitchinson, 1991). Similar restrictions were given to women in Victorian England by physican Charltes Knowlton (1891) who warned women to avoid "indigestible food, dancing in warm rooms, sudden exposure to cold or wet, and mental agitations" (p.36). Knowlton (1891) also believed menstruation was a disease that women suffered from. In his book Fruits of Philosophy that during menstruation or the 'monthlies', "various un-pleasant feelings are liable to attend it; but when it is attended with severe pain, as it not infrequently is, it becomes a disease, and the woman is not likely to conceive until it be cured" (p.36).

The association between menstruation and women's inferiority, a belief held originally by Aristotle, still existed among some physicians during the 19th century. Some of these physicians also argued that women became hysterical during menstruation and more susceptible to emotional breakdowns (Mitchinson, 1991). This belief was supported by the idea that the physiological, emotional and mental components of women were interdependent. Therefore, any alteration in a women's menstrual cycle was 
believed to result in a mental illness and any shift in a woman's mood could cause menstrual obstructions (Shuttleworth, 1990).

Although there were many claims regarding women's menstruation and the detrimental effect on their bodies, there was little understanding of the menstrual cycle. Several theories emerged during this century to explain the physiology of the menstrual cycle and why it occurred. One theory by F.K. Kiwisch in 1851 argued that the nervous and vascular system played a role in the ovaries which resulted in the flow of menstrual blood (Mitchinson, 1991). It was not until the mid-1890's when experimental research on the ovaries provided evidence of an association between the ovaries and menstruation (Mitchinson, 1991). However, this knowledge was limited to the extent that removal of the ovaries resulted in loss of menstruation. Many physicians looked towards the animal kingdom and compared menstruation in women to female animals in heat (Mitchinson, 1991). This analogy to animals highlights yet another example of how women were deemed inferior to men. Male physicians' unease with menstruation also contributed to the lack of understanding of the menstrual cycle and a greater focus on a male centered model in medicine.

This male dominated medical sphere was made explicit within medical textbooks that discussed women's bodies and provided health advice to male practitioners. Even the advertising of domestic medicine was geared towards the male head of households (Shuttleworth, 1990). However, beginning in the mid Victorian era, advertising of menstrual products in newspapers shifted to target female audiences. These advertisements proclaimed to resolve menstrual symptoms including obstructions, 
cessation and irregularities through pills endorsed by male physicians. Newspaper advertisements began to associate menstruation with mental health and warned that menstrual disruptions could result in insanity if symptoms were ignored (Shuttleworth, 1990).

Emphasis on associations between women and the body were emphasized during the 19th century. Victorian physicians accentuated biological differences between the female and male body to reinforce physical gender dichotomies (Shuttleworth, 1990). Shields (2007) argues that this gender dichotomy extended to social differences for men and women as well which were based upon underlying 'natural' distinctions. Efforts to polarize male and female bodies during the 19th century highlights a shift from Laqueur's (1990) one sex theory where female bodies were seen analogous to male bodes in medieval medicine. Instead, natural differences between men and women, such as menstruation, that were argued to exact a greater toll on women's physical development, were used to justify male superiority.

20th Century United States, Canada and England

The evolution of menstrual products and marketing led to a shift in how menstruation was perceived in North America during the 20th century. This radical shift in thought was influenced by the first advertising campaign for sanitary pads by Kotex in 1921 (Mandziuk, 2010). Kotex's campaign presented a 'modern' understanding of menstruation during a period when women's social roles were undergoing transformation and being redefined. Part of this 'modern' image was relinquishing homemade menstrual clothes from the early 19 th century and switching to the convenience and associated 
luxury of disposable pads (Freidenfelds, 2005). This coincided with a change in women's role in society, with women beginning to move beyond the domestic sphere. Kotex advertising shaped the new modern woman as someone who displayed her body yet concealed menstruation (Mandziuk, 2010). This concealment was made possible through the use of Kotex products and this became a critical message in their campaign. This concealment was partly due to a new lifestyle for women with involvement in school, work and activities emerging outside the home demanding greater attention to selfpresentation (Freidenfelds, 2009). This new lifestyle for women provided an important platform for the advertisement of sanitary products which intersected with emerging American values of modernity.

This 'modern' view of menstruation also derived from the progressive values of the 20th century of technological advancement and scientific rationality, including the ability to control social and natural processes. The era of industrialization led to a culture that embraced the values of efficiency and discipline. These values transferred over to the body where control and discipline were expected, especially when it came to the issue of menstruation (Freidenfelds, 2009). This value translated to the type of model selected for the Kotex ads; the women selected had slender and long bodies. Thin women represented the cultural ideal of having control over their bodies as well as economic, romantic and social endeavors (Mandziuk, 2010). This thin body type also 'classed;' it was contrasted to the shorter and plumper bodies of the servants or working class.

Two events then occurred that strongly informed the focus on greater sanitation, including menstrual products. The first was World War I, which was followed by an 
epidemic of influenza. This resulted in a greater focus on sanitation, with companies utilizing this public fear for greater advertising potential. Menstrual pads were described as 'sanitary', made from 'surgical cotton' and 'hygienically sealed in individual containers' (Houppert, 1999, p.6). This new attention to hygiene was used in menstrual pad campaigns. Kotex, for example, appealed to women to become more aware of germs associated with traditional methods of menstrual blood collection (Mandziuk, 2010). Advancements in science and sanitation were funneled into constructing an image of the 'modern' woman who kept her body clean and controlled.

Greater medical intervention during the 20th century may have led to increased surveillance of the body by physicians. Literature for adolescent girls warned them of the pain and feelings of illness that accompanied menstruation. Girls and women were also advised to reduce exercise, studying and reading during menstruation for fear their bodies were too sensitive to handle such activities. The majority of advice literature included medical language and descriptions of the reproductive system, reflecting a medically orientated culture (Fingerson, 2005). This discourse was a contributing factor in medicalizing menstruation, wherein menstruation and associated discomforts came to be defined as an illness that needed intervention by medical experts (Ussher, 1989). The first record of this medicalization in the literature was in 1931 by gynecologist Robert $\mathrm{T}$. Frank who used the term 'premenstrual tension' (PMT) to describe a series of symptoms that occurred prior to menstruation. PMT was the precursor to the now familiar term PMS which became included as a psychiatric illness in the DSM in. PMS became a highly recognized and used term among medical practitioners which replaced previous accounts 
of 'hysteria' in women. The renaming of PMT to PMS may have augmented the scientific validity of the term as an illness in the medical community (Ussher, 1989).

Psychological tests on menstrual and premenstrual women began to be conducted in 1942 to help treat Premenstrual Syndrome (PMS) (Delany et al., 1976). These tests were supplemented by emerging psychological theories in the 20th century that attempted to explain the aetiology of PMS and how it could be medically treated. While the 19th century Victorian physicians focused on ovaries and the uterus as the cause of a woman's well-being, a shift occurred in the 20th century with greater attention to the role of hormones (Malson \& Nasser, 2007). This was reflected in new theories that deemed imbalances of female sex hormones, estrogen progesterone, and dopamine action as reasons for PMS. Other psychological theories of PMS offered by experts included rejection of femininity, acceptance of femininity, life stress and marital problems among others (Ussher, 1989). Despite the greater medicalization of PMS through medical intervention and psychological theories, some women viewed the label of PMS more positively, as in feeling more creative (Parlee, 1973). (This perspective will be further explored in Chapter 5.)

With the introduction of PMT and PMS as a medical disorder, studies began to be conducted on the link between menstruation and crime rates. By natural order, women were believed to be incapable of violence because of their supposed angelical nature (Easteal, 1991). Women who committed crime were essentially seen as unnatural. Their crimes were believed to be an act of insanity linked to the menstrual cycle which may have altered hormones in the body (Easteal, 1991). In a study conducted by British 
physician Katharina Dalton (1961) in the 1960's, female prisoners were interviewed to assess whether their crimes were more likely to have been committed during the premenstruum or menstrual phrase. This research was based on previous reports that stated menstruating women were more likely to be in accidents, have deterioration in work or behaviour and be admitted to a hospital for a psychiatric illness (Dalton, 1959). Dalton (1961) concluded from her study that half of the women she interviewed committed a crime during the premenstrual or menstrual phrase. In fact, she claims that for 63 percent of the women, their crime was during the premenstruum which Dalton attributes to the symptoms of premenstrual tension. Dalton (1961) claimed that PMT symptoms such as irritability and temper "may lead to violence and assault, lethargy may lead to child neglect, and depression to suicide" (p.1753). This link between crime and the menstrual cycle was similarly supported by American physician W.R. Cooke who in his presidential address to the American Association of Obstetricians, Gynecologists, and Abdominal Surgeons presented data from a Parisian prefect of police that 84 percent of crime by women was committed during the premenstrual and beginning phases of the menstrual cycle (Horney, 1978).

The medicalization of menstruation through PMT and PMS attempted by some psychiatrists in North America and England was considered reason for temporary insanity for causing crimes based upon symptoms such as loss of self-control (Delaney et al. 1976). Other attempts to justify PMS for crimes included using PMS as a tactic in plea bargaining for reduced sentences (Delaney et al. 1976). For example, in Canada during the early 1980's, a woman accused of shoplifting had her charges dropped in court when 
evidence was shown that she had PMS since she was a teenager (Easteal, 1991). Other similar court cases appeared during the 1980's in Canada and the United States where women's sentences were mitigated based upon evidence of suffering from symptoms of PMS when their crimes were committed (Easteal, 1991).

Along with crime, any type of menstrual irregularity was generally associated with insanity including schizophrenia or postpartum depression (Delaney et al. 1976). Suicides were also argued to be more common during the midluteal phrase of menstruation which accounted for days 17 to 23 of a women's menstrual cycle (Delaney et al. 1976). A study conducted in 1968 stated that fifty-nine women had attempted to harm themselves during the premenstrual phrase (Delaney et al, 1976). However, Delaney et al (1976) have argued that the previous studies do not take into account environmental factors which have shown to be highly influential.

\section{Summary}

This chapter provided a selective review of historical perspectives on menstruation during key periods in Western history. From Ancient Greece to 20th century America, menstruation has been positioned on a spectrum anchored at either end by positive and negative perspectives. Negatives perspectives of menstruation were often projected by male philosophers and medical practitioners. These negative perceptions, such as poisonous, polluting and dangerous, were positioned around menstruation and transcended many centuries. Since Aristotle, a link between menstruation and female inferiority was made and has been perpetuated by male dominant groups into the 20th century. These claims about menstruation and women's bodies were often made with no 
evidence and little understanding of the menstrual cycle. However, Hindson (2009) posited that positive perspectives of menstruation also existed throughout western history yet have been overlooked. These included menstruation being a sign of a healthy body and as beneficial to pregnancy. These polarizing perspectives have occurred simultaneously, suggesting that menstruation is a complex bodily function onto which many cultural anxieties, and scientific agendas, are projected.

A closer look at these menstrual perspectives in relation to female education in chapters 3, 4 and 5 will be explored in greater depth through my research question "What discourses has science constructed around the relationship between menstruation and female cognitive ability from the late 1800 s to today?" 
Chapter 3: Menstruation and Denial to Higher Education (Clarke, Hall)

Historically, menstruation has been viewed from both positive and negative perspectives as highlighted in Chapter 2. In this chapter, I focus my attention on late 19th and early 20th century America, a period during which menstruation became constructed as a barrier to women wishing to access higher education. Male physicians warned of the supposed dangers studying would impose upon female reproductive systems. Women were warned against higher education and redirected toward traditional and 'safe' domestic roles such as wife and mother. This chapter will focus on two key figures, Edward H. Clarke (1820-1877) and G. Stanley Hall (1844-1924), who were highly influential in the late 19th century in discouraging women from seeking higher education or coeducation for fear that it would harm their bodies and minds. Theories posited by Clarke and Hall were highly regarded and supported by many prominent medical practitioners during this period. I will explore the work of these practitioners to demonstrate the widespread credence given to the theory of menstrual invalidism. Feminists who opposed Hall and Clarke's claims will be introduced in this chapter and explored in greater depth in chapter 4. A view of how Hall and Clarke and feminists in the 19th and early 20th century were received by the public will be examined through historical newspapers from the Library of Congress Chronicling America, American Memory Project and ProQuest online databases. I will also explore the relationship of Clarke and Hall's arguments to shifting gender roles in late 19th century America, especially the view that women were risking their femininity or 'womanhood' if they considered higher education during this era in American history. Tuana's taxonomy of 
ignorance will be applied to this chapter in framing Hall and Clarke's ignorance around feminist research which perpetuated menstrual invalidism throughout the 19th and early 20th century.

\section{Clarke, Education and Women's Physiology}

Harvard Professor and physician Edward Clarke was a central figure in the opposition to women entering higher education. Clarke was born in Norton, Massachusetts in 1820. He completed his degree at Harvard University in 1841 before pursuing a medical degree in Pennsylvania. He then settled in Boston where he practised medicine and taught as a professor at the Medical School of Harvard University. In 1855, Clarke was distinguished by Harvard University as the chosen Professor of Materia Medica which he held until 1872 when he resigned (American Academy of Arts \& Sciences, 1877-1878). In 1873, Clarke published Sex in Education, which became one of his most influential works. During his career, Clarke wrote other significant medical works including The Building of a Brain (1874), a follow-up book to Sex and Education. This book focused on the development of young women in the chapter "An Error in Female Building”. Here, Clarke addressed several letters and excerpts from parents who wrote of their daughters' suffering from the labours of education. Letters from medical practitioners, educators and professors who supported Clarke's work on women and education were also included.

Clarke argued in Sex and Education that the education of women would result in the weakening of a woman's reproductive functioning as studying would consume the blood and energy required for menstruation (Delany et al 1976). Clarke's book Sex in 
Education (1873) had considerable influence in the 19th century (see Ehrenreich \& English, 2005). He believed that men and women shared identical physiology with the exception of the reproductive system. Women were obligated to care for and nurture their reproductive organs which could prove to be a source of power and strength. However, women who were neglectful of them suffered from weakness of the body and mind. The greatest neglect according to Clarke was overworking the female brain. Clarke (1873) stated that "improper methods of study, and a disregard of the reproductive apparatus and its functions, during the educational life of girls, are the sole causes of female diseases" (p.62). Clarke maintained that a body was not able to divide its functions without consequences. He gave the example that students who overworked their brains could expect to possess monstrous brains and stunted bodies. He was especially concerned with young female students, fearing that studying during the development of their reproductive systems would result in excess blood flowing to the brain and limited blood flowing to their reproductive organs. Clarke voiced his concern over the number of female graduates "who have been permanently disabled to a greater or less degree" resulting in great alarm (p.63). Educated women were argued to be more susceptible to amenorrhoea, dysmenorrhoea, menorrhagia, hysteria, chorea, anemia, abortions and even sterility (Clarke, 1873, p.48).

\section{Clarke's Medical Case Studies}

Clarke used case studies from several women to provide evidence of the effects of studying on ill health (Bullough \&Vough 1973). They were labelled as Miss A, B, C, D, E, F, and G in Sex in Education. All had developed illnesses that, Clarke argued, were the 
consequence of overworking the brain. All the women in the case studies were described as being initially healthy and young. Their symptoms were deemed by Clarke to have begun during the period when the women entered higher education or masculine professions. Miss C, a twenty year old bookkeeper whose occupation required long hours of standing from Monday to Saturday, complained of backache and general debility, among other symptoms. Miss $\mathrm{C}$ wrote to Clarke of her symptoms and to seek medical advice. Clarke responded by advising her to “do your work in a woman's way, not copying a man's fashion, and you will need very little apothecary's stuff' (Clarke, 1873, p.77). Clarke's response reveals the belief that women's bodies were limited in their abilities to work certain professions. Women, he argued would experience consequences and punishments "for being educated and working just like boys" (p.78).

Clarke argued that America's educational system was at fault for these problems. He claimed that the "regimen of our schools, colleges, and social life that requires girls to walk, work, stand, study, recite, and dance at all times as boys can and should, may shut the uterine portals of the blood up, and keep poison in, as well as open them, and let life out” (p.78). Clarke further supported his claim by introducing the case study of Miss D, who at the age of 14, entered Vassar College as a healthy girl. By the age of 15, Miss D began to suffer from ailments such as fainting, and physical pain associated with dysmenorrhoea which occurred two to three days every month. Clarke wrote that after her graduation from Vassar at the age of nineteen, Miss D suffered from amenorrhoea and hysteria. Clarke postulated that her previously healthy condition deteriorated the longer she was in school. During this period, Clarke stated, the woman's reproductive system 
developed but the body's vital resources were "turned steadily to the brain, and away from the ovaries and their accessories" (p.83). Her symptoms, which gradually become more severe, were the body's way of warning that the reproductive organs were not receiving sufficient nutrition.

Clarke's other case studies follow similar suit to the examples of Miss B and Miss $\mathrm{G}$ who suffered from overworking the brain or body. He used the seven clinical cases as evidence that the American education system failed women by invoking mental strain and subsequently affecting their health. Clarke did not believe that all women who sought higher education were susceptible to ill health. However, he argued that the high rate of female graduates who did suffer were sufficient cause for great alarm and required immediate intervention.

Clarke's arguments were challenged by psychologist Leta S. Hollingworth who critiqued the authority that male physicians and psychologists had over women's bodies. This included the majority of medical studies conducted on women which were performed by male physicians. She characterized medical studies, such as the clinical cases performed by Clarke, as unscientific and selective in choosing women who were physically ill. These results, she argued were then generalized to all women. In Clarke' case, his study of seven women formed the basis of his book Sex in Education which he used to develop his hypothesis that education harmed all women in America. In a New York Times article, Hollingworth was praised as one of the first women trained in science to conduct studies on the psychology of women which "men have never succeeded at the task" (Dorr, 1915, p.15). The article supported Hollingworth and other women who "are 
beginning to understand themselves as no male scientist can ever understand them, and they face their great problem confident that nothing in nature stands in the way of its solution" (Dorr, 1915, p.15). Hollingworth disproved Clarke's claims in her dissertation, Functional periodicity: An Experimental Study of the Mental and Motor Abilities of Women During Menstruation (1914), which revealed menstruation having no effect on women's physical and mental abilities. Hollingworth's dissertation will be further discussed in chapter 4.

\section{Clarke's Medical Advice and Proposed Intervention}

Clarke advised women as well as men to follow three general rules to promote a healthy body. These included sufficient nutrition, a regimen of mental and physical work, and adequate sleep. However, male and female bodies were physiologically different and women required other regulations to avoid strain. He stated that girls between the ages of fourteen to eighteen must have enough sleep for growth, repair, and development of their reproductive systems. Clarke also argued that women should avoid work one week of every month and to avoid intellectual strain:

A girl cannot spend more than four, or, in occasional instances, five hours of force daily upon her studies, and leave sufficient margin for the general physical growth that she must make....If she puts as much force into her brain education as a boy, the brain or the special apparatus (i.e., the reproductive system) will suffer. (Clarke, 1873, p.156-157) 
Women who did not follow his advice were at risk of ailments such as sterility, hysteria and even death (Clarke 1873). He supported his advice with education models from Germany where rest for females was practiced (see also Bullough \& Vough 1973).

Clarke mandated that co-education was at the root of a girl's ill health. He believed that the education system during the 19th century was to a great extent the cause of "the thousand ills" that plagued American women (p. 22). He warned that girls who trained and studied in the same way as boys could not maintain their health and would be susceptible to disorders of the nervous system (Clarke, 1873). He robustly challenged coeducation which he defined as the teaching of boys and girls the same material in the same place, time, and under the same methods and teachers. This identical co-education formed the basis for Clarke's argument and he highly encouraged separate methods of study for girls and boys. Clarke believed that school systems were designed around a male's physical and mental development. Even schools that only admitted girls, Clarke argued, tended to be modeled after boys' schools. Girls worked their brains studying "mathematics, botany, chemistry, German, and the like, with equal and sustained force on every day of the month" (p.126). This regimen resulted in dire consequences: young women would lose their "health, strength, blood, and nerve, by a regimen that ignores the periodical tides and reproductive apparatus of their organization" (p.127). Clarke, however, did believe that girls could learn the same material and reach similar educational levels as boys, on the condition that this education be achieved in a "women's way." As he noted, "boys must study and work in a boy's way, and girls in a girl's way" 
(p.18-19). Therefore, Clarke's solution was to implement separate educational systems for girls and boys.

Clarke received wide support for his views from other medical practitioners, public health boards, educators, professors and mothers of women who had suffered from the ills of studying. His claim for separate educational systems were endorsed by these individuals who wrote to Clarke of their own personal experiences of seeing women's deterioration from studying. Clarke published personal letters that he received from these individuals in his book Building of a Brain to further provide credence for his argument of separate education for girls and boys. One letter from D.H. Cochran, the head of the Brooklyn Collegiate and Polytechnic Institute highlights this support:

I have been compelled to the conclusion that the sexes cannot be educated together with advantage to either, and that the physical disadvantages under which she labors render it necessary that a system be devised so elastic, with so much optional work, that the female may rest, at least comparatively, as occasion requires, without her falling behind, or becoming a burden to the class or the teacher. I urge the separate higher education of females solely upon physical grounds (Clarke, 1874, p.112)

Other educators revealed similar views including one teacher with 40 years of experience who expressed his opinions on the "physical evils of our present modes of our female education" (p.123). Other views included a letter which is simply titled "From a Mother" (p.90). Here, a mother expressed her growing concerns over her daughter whose health deteriorated when she had entered an institute for young women. Her daughter suffered 
from rheumatism, swollen limb and kidney damage which she passed away from. However, despite lack of firm evidence of the daughter's illness, her mother remained "convinced that what she did have was brought on by incessant study when she should have rested" (p.97). The anecdote of the daughter and the two educators, along with the other personal letters published by Clarke reveal a common thread. Similar to Clarke, these experiences lacked any form of empirical evidence that studying deteriorated women's health but instead was solely based upon opinions and interpretations.

Despite support from the medical sphere and other educators, public support of Clarke's ideas were fairly divided. In an article in The Princeton Union, Clarke's works including Sex and Education and The Building of a Brain were described as provoking "more or less sharp antagonism" (1878). Similarly, a book review in the Herald and Tribune commented on Sex in Education as causing "quite a stir and called forth much criticism both favorable and unfavorable" (1895). Yet, the review continued on to describe The Building of a Brain as strengthening the position that there were faults in female education. Aside from these reviews, little coverage existed on Clarke in newspapers during his lifetime.

Clarke's writings suggest that there was little division between his personal and political views. Clarke's belief in separate education systems for boys and girls was also derived from his religious beliefs. He stated that "identical education of the two sexes is a crime before God and humanity" (p.127). Clarke wrote that women and instructors should read and consult the old Levitical law. He argued that "there is nothing to be ashamed of in a woman's organization, and let her whole education and life be guided by the divine 
requirements of her system" (p.45). It is foolish and even criminal behavior on the part of women to ignore one of their most important abilities, reproduction. Clarke argued that each generation of women had increasingly neglected this God-given ability, resulting in weaker female bodies. He argued that these natural abilities in women were biologically innate and could not be ignored:

The problem of women's sphere, to use the modern phrase, is not to be solved by applying to it abstract principles of right and wrong. Its solution must be obtained from physiology, not from ethics or metaphysics...Without denying the selfevident proposition, that whatever a woman can do, she has a right to do, the question arises, What can she do? (Clarke, 1873, p.12)

The foundation for Clarke's medical theories were scientific writings by Herbert Spencer, Charles Darwin, Henry Maudsley, Hermann von Helmholtz and Alexander Bain. Clarke attempted to use their writings to support his belief that women and men differed due to the natural process of evolution. It was the responsibility of civilization, according to Clarke, to cultivate this difference instead of hiding or abolishing it (Rosenberg, 1982).

Clarke's philosophy on the separate education of boys and girls was also closely linked to the Victorian doctrine of separate spheres. This emphasized the idea that social roles for men and women were rooted in biology. This doctrine stated men were naturally more assertive and rational while women were emotional and passive (Shields, 2007). However, in the late 19th and 20th century, women, especially professional women, began questioning and challenging the Victorian doctrine of separate spheres (Rosenberg, 1982). This included physician Mary Putnam Jacobi who received widespread support for 
her research on the advancement of women which she advocated throughout the United States. Jacobi’s 1877 essay, “Do Women Require Mental and Bodily Rest during Menstruation?", was one of the first works to challenge menstrual debilitation. In 1893, Jacobi spoke about women's advancement in science at the women's congress in Chicago and was joined by activist Julia Ward Howe among other feminists. The congresswas attended by "thousands of women" as reported by The Rock Island Daily Angus (1893, p.1). Similar support was received at Jacobi's speech delivered at the Constitutional Convention of the state of New York in 1894, which attracted widespread attention. The Bismarck Weekly Tribune described Jacobi's speech as "one of the most remarkable speeches ever made by a woman" that presented "erudite, logical and dignified arguments" (1894, p.6). Jacobi's speeches were similarly praised by the Norfolk Virginian newspaper who stated she presented the strongest arguments in favour of women's suffrage which would "win converts to the cause in great numbers"(1895, p.8). After a poll of the brainiest woman in New York, The Saint Paul Daily Globe reported Jacobi as a clear favourite (1895). Howe was similarly received by the American public on her views of emancipation of women and was titled as "woman's beloved champion" (Bismarck Daily Tribune, 1909, p.2). In the New York Tribune in 1919, Howe was named "friend of America" (p.8) and was introduced as "Julia Ward Howe of the universe" at the National Federation of Women's Club held in Boston for her widespread popularity beyond the United States (Bismarck Daily Tribune, 1908, p.2). A further in depth analysis of Jacobi and Howe's arguments will be explored in chapter 4. 
Despite this public support of Jacobi and Howe, Clarke remained ignorant of their arguments and other feminist research. This highlights Tuana's fourth category, willful ignorance, which is ignorance that is actively produced and maintained over time. Clarke exemplified this ignorance by intentionally not acknowledging research that offered evidence against his arguments. This included studies by physician Jacobi which revealed that physical and mental labour had no effect on a woman's reproductive health. Instead, Jacobi, Mosher as well as Howe provided alternative explanations for why some women suffered from menstrual difficulties, including restrictive female clothing. However, Clarke continued to produce works that reinforced female inferiority and menstrual invalidism despite having little scientific evidence. Additionally, other male physicians continued to cite Clarke's work and produce similar theories around higher education affecting women's health despite evidence being produced by feminists that debunked such claims (see Clouston, 1883, Darnall, 1901, Dyke 1905, Engelmann, 1900, Kellogg,1882, Maudsley, 1884, Parsons, 1907, Walling, 1904). This further perpetuated and reproduced beliefs of menstrual invalidism after Clarke's death. Clarke, as a male physician, held a privileged position in society, enabling him to produce oppression against women by ignoring feminist narratives deemed to be inferior. Clarke, holding this position of power as a medical professional, held himself as well as the medical institution responsible for the physical, moral, spiritual health of the Victorian nation (Haller \& Haller, 1974). This resulted in male physicians exerting "all their professional authority to bear against those elements which threatened the stability, if not the very existence, of society" and "this certainly included the women's right movement" (Haller 
\& Haller, 1974, p.xi). This weaves into Tuana's fifth category of ignorance, ignorance produced by the construction of epistemically disadvantaged identities, meaning that knowledge constructed by individuals or groups labelled as 'non knowers' is ignored. In this example, feminists including Jacobi, Howe and Mosher's arguments were ignored by Clarke and other male physicians whom marginalized them to be 'non knowers'.

\section{G. Stanley Hall and Women's Higher Education}

G. Stanley Hall advocated similar views to Clarke around women's higher education. G. Stanley Hall was an eminent American psychologist who received the first Psychology $\mathrm{PhD}$ in America and established psychology as an academic discipline with William James (Ross, 1972). Born in 1844 in Massachusetts and raised in a small farming community, Hall had ambition and desire for his own higher education (Ross, 1972). Hall initially enrolled in theology school and spent two years there before deciding to study philosophy at the University of Berlin. His move to Germany and his new exposure to philosophy as well as psychology led Hall to re-envision psychology in America. He went on to become the founder and president of Clark University, the first president of the American Psychological Association in 1892, and a significant institutionalizer of the new psychology in the United States.

Hall had similar beliefs to Clarke in terms of creating separate educational systems for boys and girls (Strickland \& Burgess, 1965). He is known as one of the early 20th century leaders in the argument against co-education (Diehl, 1986). His ideas not only shaped psychology's views of women and sex differences but also societal and cultural perspectives on gender roles. This section will focus on two works by Hall, 
Adolescence: Its Psychology and its Relations to Physiology, Anthropology, Sociology, Sex, Crime, Religion and Education (1905) and Youth: Its Education, Regimen, and Hygiene (1906). Both highlight Hall's theories around the education of girls and women. I will focus specifically on two chapters "Adolescent Girls and their Education" and "The Education of Girls."

Hall's two volume book, Adolescence: Its Psychology and its Relations to Physiology, Anthropology, Sociology Sex, Crime, Religion and Education (1905), first published in 1904, examined sex differences between men and women and how this influenced psychological development during adolescence. His book was received and endorsed among educators, however the book was highly critiqued by other leading psychologists in the 20th century, such as Edward Thorndike (Diehl, 1986). His chapter "Adolescent Girls and their Education" which appears in volume II, examined studies conducted on college women on the topics of health, marriage and birth rates. One of these studies, conducted by John Dewey (1859-1952), looked at women's health before and after they entered college. Dewey, an American philosopher, psychologist and educational reformer, found that of 290 college girls, 78.1 percent reported good health when they entered college, 74.9 percent had good health during college and 77.9 percent after college. Additionally, 53 percent of women reported suffered from pain and menstrual irregularity during pubescence which increased to 66 percent during college. Another study by Dewey revealed that 20.5 percent of women who had entered college one to two years after they began menstruating reported bad health. This declined to 17.7 percent for women who had started college three to five years after this time and 15.4 
percent for women starting five years or later. Of the same women, 83 percent had good health after graduation and 17 percent reported ill health. Additional statistics were conducted on menstruation and the college experience. These statistics revealed that 55 percent of women who attended women-only colleges and 25 percent in coeducational colleges reported abstinence from exercising or studying during menstruation. Hall concluded from the studies that young women were more susceptible to ill health when they were in college. Hall also used supporting evidence from physician George $\mathrm{J}$. Engelmann who found 50 percent of 4,873 cases of school and college women suffered from irregularity of menstruation. This evidence led Hall to argue that mental strain increasingly affected menstruation in schoolgirls.

Hall also examined studies on the fertility rates of educated women. A study by physician Nathan Allen stated that within New England, there had been a steady decline in the birth rate during the past century. Of the New England women who had children, Allen estimated that only half could properly nurse them. He credited this to undeveloped mammary glands, poor digestion and nervousness. Women's infertility was described by Herbert Spencer as being the result of "mental labor carried to excess" (as cited in Hall, 1904, p.602). Hall used Spencer's quote as an explanation for the lack of children from female college graduates. Hall also used evidence from a study published in 1885 by Annie G. Howes, a chairman of the Special Committee of the Association of Collegiate Alumnae, in collaboration with the Massachusetts Bureau of Statistics of Labor. Howes, a supporter of women's higher education, set out to test claims of physical incapacity of college women. In Howes (1885) study, only 196 women from a total of 705 graduates 
were married and 66 percent of those married had children. Women who did not marry before the age of 30 were viewed as being unable to have more than two children. Hall argued that the age at which women married determined their number of children. Based on this study, Hall perceived women who went to college as more likely to marry later in life or to remain unmarried which adversely affected the birth rate in America. However, Hall ignored other findings from Howes's studies which revealed the benefits of a college education for women. Howes (1885) reported that 78 percent of the 705 female college graduates reported their health between fair to excellent. Of the 705 students, 36 women did not classify themselves in the study. Howes argued that if these remaining 36 women were included under the heading 'fair health', 83 percent of the total 705 students had 'fair' to 'excellent health'. This only left the remaining 17 percent of female college graduates as reporting 'ill health'. Howes also points out that 20 percent of the same students claimed 'ill health' when they first entered college. This highlighted a 3 percent decrease in women's ill health during college. This decrease in women's ill health, Howes argued, was a positive benefit of college training for women. This ignorance through omission of the data by Hall to fit his hypotheses highlights Tuana's fourth category, willful ignorance, which is ignorance that is actively produced and maintained over time. Tuana states that this ignorance is in the interests of certain individuals or groups who choose to be ignorant. In this case, it was in Hall's interest to be ignorant of the positive aspects mentioned by Howes.

Hall also ignored studies that provided other explanations for the decreasing marriage rate of women. A study by female psychologist Milicent Shinn challenged 
societal notions of college women being less likely to marry. Her article, The Marriage Rate of College Women (1895), which was published nine years prior to Hall's book, revealed how the rates of college women were misleading. The lower marriage rates of higher educated women were not a result of physical or personality attributes that made them unmarriageable or a lack of interest in marriage. Instead, Shinn argued that college women could support themselves financially and they could also be more selective in whom they married. Additionally, she stated that some men disliked college women who could be their intellectual superiors (Rodkey, 2010).

Hall asserted that medical studies such as those performed by Dewey and Engelmann revealed women were afflicted by their menstrual cycle during college. Studies on the marriage and birth rates of college women revealed a decrease in both the number of women marrying and the number of children per family. Hall (1904) stated "the more scholastic the education of women, the fewer children and the harder, more dangerous, and more dreaded is parturition, and the less the ability to nurse children" (p. 614). This troubled Hall who viewed motherhood and marriage as essential roles to being a woman. Natural differences between males and females were also crucial to Hall's propositions of separate educational systems. His acceptance of the variability hypothesis demonstrated his belief in the naturally rooted biological differences between the sexes and how this affected intellectual capability for women.

\section{G. Stanley Hall and the Variability Hypothesis}

Hall wrote about the numerous differences between the sexes, including physical and emotional traits. He referenced studies and authors who described sex differences in 
weight, height, lung capacity, pulse, illnesses each sex was more likely to contract, brain weight, psychological disorders, dexterity, personality traits, crime rates, altruism and accomplishments among many others. Hall also supported the variability hypothesis, a popular theory in the 19th and 20th century that argued that the male of the species exhibited greater variability than the female. This greater variability in men was evidenced by the belief that there were more extremes in male intelligence, including male geniuses. The lack of eminent women, according to the theory, was a consequence of less variability in women (Shields, 1982). Hall (1905) reinforced this belief in stating that a "woman is best in acting and judging in ordinary matters; man in those that are extraordinary" (p. 567). Additionally, Hall claimed that because women had less variation from the average, their mental capacities were suited to reproducing knowledge instead of producing new knowledge. On the one hand, women's social characteristics and emotional traits led to Hall describing them as closer to children in their behaviour. On the other hand, Hall (1905) described the male as the "agent of variation and progress, and transmits variations best, so that perhaps the male cell and sex itself originated in order to produce variation" (p. 567). Males were therefore seen by Hall as responsible for the progression of culture and knowledge, while females were better suited to roles outside of academia such as motherhood. These 'natural' differences between males and females and the variability hypothesis supported Hall's opposition to coeducation (see also Shields, 1975).

Psychologist Leta Hollingworth challenged the variability hypothesis and the male scientists such as Hall who endorsed it. Similar to her accusations of Clarke, 
Hollingworth argued that a lack of scientific evidence existed to support such biological theories as the variability hypothesis. She decided to empirically study the variability hypothesis as a way to disprove ideas surrounding female inferiority and reveal the many biases that infiltrated scientific work produced by male scientists.

\section{Women's Education: A Separate Sphere}

G. Stanley Hall fought against coeducation of males and females for fear it harmed a women's health and her femininity. Following his book on Adolescence, Hall continued to publish works on women and education including Youth: Its Education, Regimen, and Hygiene in 1906. His chapter "The Education of Girls" addressed the issues of coeducation and how it affected girls. Hall stated that women's battle for equal education has been won by their academic achievements which have "forced conservative minds to admit that her intellect is not inferior to that of man" (1906, p. 277). However, Hall still remained a proponent of separate educational systems for girls and boys during adolescence. He placed great importance on human development during adolescence or between the ages of 14 to 25 . This period of growth was especially important for adolescent growth of girls according to Hall as they were susceptible to damaging their reproductive organs. He believed that it was therefore especially important for adolescent

girls and boys to have separate educational systems due to their biological differences that developed after puberty. Girls could not be held to the same standards of strenuous mental work that boys required. Therefore women needed to attain higher education in a woman's way. In his words: 
Moreover, nature decrees that with advancing civilization the sexes shall not approximate, but differentiate, and we shall probably be obligated to carry sex distinctions, at least of method, into many if not most of the topics of the higher education. Now that woman has by general consent attained the right to the best that man has, she must seek a training that fits her own nature as well or better. So long as she strives to be manlike she will be inferior and a pinchbeck imitation, but she must develop a new sphere that shall be like the rich field of the cloth of gold for the best instincts of her nature (Hall, 1906 p.283-284).

Hall argued that institutions such as schools should be responsible for guiding natural and biological differences between men and women by encouraging boys to embody manly characteristics and women to be more womanly. Neither men nor women should copy or impose their natural characteristics on each other. The beginning of puberty and adolescence marked these sexual differences that naturally created divisions between girls and boys. It was at this stage that Hall believed coeducation should end until greater maturity was reached by men and women between the ages of 18 to 20 when they entered college and university.

Hall asserted the stage of adolescence when girls began menstruating as a time when they should abstain from intellectual stress. He praised Clarke for raising important issues regarding intellectual strain on the female menstrual cycle. However, Hall stated that this reasoning was not the sole focus of his contempt for coeducation. Hall instead focused on how coeducation during adolescence affected femininity and gender roles for women. Hall posited that girls were more likely to choose male ideals while ignoring 
feminine principles. He quoted writer, W.G. Chambers, who expressed similar distress by stating "unless there is a change of trend, we shall soon have a female sex without a female character" (as cited in Hall, 1906, p.287). School teachers only perpetuated this loss of female character, argued Hall, by invoking and imposing their masculine ideals which confined the development of womanhood. By nature, Hall believed women were naturally more prone to domestic roles and parenting. However, because higher education was based upon male ideals, it took these roles away from women. Therefore, boys and girls needed separate methods of work and teaching regimens.

Excluded from this female curriculum was any form of "hard" science or medicine. Trecker (1974) argues that this was a way to preserve masculine disciplines during the 19th and 20th century; a period when an increasing number of women were seeking higher education and becoming professional and economic competitors to men. Hall's new educational system for women therefore focused on feminine roles which he believed could produce the ideal woman for society. This meant that women who ventured beyond the domestic sphere, such as female physicians, were viewed as anomalies (Morantz-Sanchez, 1985).

Coeducation not only affected girls but boys as well. Having girls in the classroom resulted in the feminization of self-discipline, school spirit, and personal characteristics which Hall deemed deleterious for the development of boys. Hall feared that coeducation and civilization would produce boys who were effeminate and stripped of American manhood. He was especially threatened by emerging Victorian ideals of self-restrained manliness including sexual self-restraint and delayed gratification which he argued made 
boys weak (Bederman, 1995). Hall's solution to this effeminacy was educators who could produce virile men for society. Bederman (1995) argues that Hall's theory of pedagogy was based upon the idea that small boys were analogous to savages by embodying masculine traits of power and strength. Education, Hall believed, was a way to foster these characteristics for boys. Just as education could produce the ideal woman, tailored education for boys could make real men. This was one more argument for Hall's proposition of implementing separate educational spheres for men and women.

Being a true woman according to Hall meant being a mother and a wife. Women who did not marry suffered from deterioration, including symptoms of invalidism, lassitude, life dissatisfaction and mourning among others. As mentioned previously, Hall reported a decrease in the rate of college women who married as well as they age that they married. Women who did not marry by the age of 30 resented other women with children, craved work or travel or suffered from feelings of discomfort. Although the greatest danger to women, stated Hall, were the methods used for higher education of women, even women's colleges failed to properly teach women as they did not consider the psychological and physiological differences between males and females that were essential in the pedagogy of women. Additionally, women's colleges trained women to be independent and self-supportive yet failed to teach women about motherhood and matrimony which Hall considered to be essential. Hall, as well as Clarke, believed women should be educated for more traditional roles of childrearing, homemaking or nurturing professions. In an ideal society, Hall asserted, “women's education should focus on motherhood and wifehood, and seek in every way to magnify these functions and to 
invest them with honor" (Hall, 1904, p.610-611). The ideal training timeframe for girls was between the ages of 12 into their early 30 's, which was a period he considered most favourable to motherhood. The training institution would be an outdoor retreat that included hills for climbing, water to go boating, gardens, forests, and playgrounds for tennis and golf. He believed connecting with nature helped develop poise and character for women. This ideal school also offered domesticity courses and therefore included a laboratory composed of items such as kitchen appliances, closets, bedrooms and a diningroom where women would be taught household responsibilities. Lessons on maternity and motherhood would also be taught from a young age. However, women should receive a limited amount of work and needed to restrict their studies to protect their health, asserted Hall.

Physical health was one of Hall's main concern for women during this period of developing motherhood. He references Clarke's writings on periodicity which he claims was one of the greatest triumphs in a woman's life. Like Clarke, he described the ideal school as providing a period of rest and leisure for women during menstruation. Women, he asserted, should realize that "to be is greater than to do" (Hall, 1906, p.313).

Selective studies on female college students served as a platform for Hall's argument against coeducation. This selection of studies by Hall highlights Tuana's fourth category of ignorance, willful ignorance, which was previously applied to Clarke. Hall, as well as Clarke, made assumptions about women that often were scientifically unsupported. Hall's selection of studies and ignorance of others to support his hypotheses emphasizes this willful ignorance. Feminists such as Milicent Shinn who produced 
studies that revealed alternative explanations for why the marriage rate was decreasing were ignored by Hall. Similarly, studies by Hollingworth challenged both Hall and Clarke's claims that education affected a woman's health. In fact, Hollingworth revealed that the "number of women graduated from colleges and universities in perfectly normal health increases yearly" (1914, p.97). By 1890, fifty-six thousand women were enrolled in colleges in the United States which was a fivefold increase in the past two decades (Zschoche, 1989). Newspapers articles submitted by men and women also challenged Hall's claims that education feminized boys. However, Hall's respected role as a male scientist placed him in a position of privilege. This position enabled him, as well as Clarke, to ignore individuals who were judged to produce knowledge that was not credible, emphasizing Tuana's fifth category, ignorance produced by the construction of epistemically disadvantaged identities. This largely included individuals who were not male and within a psychological or medical sphere.

\section{Supporters of Clarke and G. Stanley Hall}

Although Clarke's theory had a significant amount of support, initially there were some unfavourable reactions to his work. Critics argued that Clarke generalized his clinical case studies and there was no scientific evidence for his argument. There was even suspicion that Clarke's claims were an attempt to end the debate surrounding admission of female students to Harvard University (Bullough \& Vough, 1973). (This view will be further explored in Chapter 4). Nevertheless, the immense support of his theory was indicated by the fact that his book Sex and Education went through seventeen editions in only thirteen years. Clarke's theory was also highly supported by other male 
physicians and researchers who conducted scientific studies on menstruating women. This included physician Havelock Ellis in 1909 who claimed that menstruation caused women to be invalids (Ellis, 1909). Similarly, Dr. William Warren Potter applauded Clarke's work and stated that many of his female patients were sterile due to inappropriate education (Verbrugge 1988). Potter (1891) asked how a woman could fulfill her destiny "if her reproductive organs are dwarfed, deformed, weakened, and diseased, by artificial causes imposed upon her during their development?" (p. 305). This opinion was also voiced by physician George J. Engelmann (1890) in his book Causes Which Imperil the Health of the American Girl, and the Necessity of Female Hygiene. Engelmann (1890) proclaimed that during puberty, girls are at the greatest risk for causing harm to their reproductive system:

It is in this period of school, the period of beginning social life, the period of learning in trades, that the nervous energies of the female are most fully engaged, and her activity is concentrated on the brain function, to the detriment of other functions, above all, the developing sexual function, the central and most important, and at that time the most readily disturbed. (p.599) Engelmann (1890) proposed a solution to the overworked and over stimulated female brain by increasing physical education, wearing less restrictive clothes and increasing individual care. He also became a supporter for social changes including fashion trends, labor and education to help decrease ill effects on women's health. Engelmann (1890) advocated that we as a nation "should endeavor to obtain the end of education in its widest senses, the development of all functions and faculties, to render the girl in every 
way fit for the life she is to enter-"to render youth beautiful, healthful, strong, and honest"” (p.604).

The topic of education and the proposed effect on women's health attracted a great deal of attention. Six highly regarded male medical doctors during this period, including William Goodell, Gaillard Thomas, James R. Chadwick, Weir Mitchell, Allen Starr and J. J. Putnam addressed this issue at a symposium in 1889. Questions such as "Does the higher education of women produce changes in the general or generative system of sufficient frequency or magnitude to lead you to disapprove of movements looking to improved mental training in females?" and "Do you think that far advanced intellectual training interferes with childbearing, directly or indirectly?" were tackled by Goodell and his medical associates (1889, p.668). Goodell (1889) concluded that prolonged brain-work and stress were detrimental to women's physical and reproductive health. He also argued that sterility, absence of sexual feeling, aversion to maternity and the long recovery period from the first labor were caused by intellectual training which interfered and stunted conception and childbearing abilities (1889, p. 669).

Psychologist Edward Thorndike also supported Hall's argument. Similar to Hall, Thorndike invoked the variability hypothesis as the basis for restricting women to certain roles. He argued that since women were more likely to have mediocre abilities and intellect, they should strive towards professions that required average abilities including teaching, nursing, medicine and architecture (Trecker, 1974). More masculine professions such as philosophy, scientific research, and administration should be left to males, who were more naturally highly gifted. 
However, similar to Clarke, Hall received mixed reviews from the American public. An address by Hall on the effeminization of boys was stated by The Wenatchee Daily World (1908) to have "stirred the delegates" of the Iowa State Teacher's Convention (p.1). Additionally, an article published in The New York Tribune (1908) by Hall on the feminization of boys as a result of the present education system produced controversial responses. Within a month of the article's publication, several retorts were printed in the same newspaper. One of the retorts described Hall's claims as "laughable" since "whatever may be the faults of the average American schoolboy, he certainly is not effeminate" (Blackwell, 1908, p.10). This author continued to state that "Dr. Hall's reactionary views on the women question in general and women's education in particular have caused his judgement to be seriously discounted by prominent educators" (Blackwell, 1908, p.10). On the other hand, Hall actively published numerous articles in newspapers and was praised by some as "the most famous exponent of pedagogy in America" (The San Francisco Call, 1898, p.9) and as a "great scientist" (The New York Tribune, 1907, p.2).

\section{Summary}

Clarke and Hall's theories around women's education had widespread support from other American male psychologists and physicians. Their condemnation of women's higher education revolved around the fear that overstressing the brain posed harm to a woman's body and mind. Clarke and Hall viewed reproduction and the roles of motherhood as imperative to being a woman. With the rise of science and technology in the 19th and 20th century, a greater emphasis was placed on distinguishing female from 
male roles. Masculine disciplines such as many scientific fields were seen as unnecessary in women's natural place as mother and wife and the continuation of the American race. Higher education was blamed for American women remaining single, marrying late and having fewer children. As Hall remarked, female colleges were training women to be independent which went against social norms. This independence struck a fear that educated women would be argumentative wives, disturb the household, and challenge authoritative opinions of their husbands and sons (Burstyn, 1980). In a similar thread, Trecker (1974) argues that this independence was considered a masculine trait and one that coincided with the power of scientific disciplines.

Hall was highly concerned about preserving masculinity which he argued was being stripped by coeducation and civilization. Women's individuality was therefore directed to domestic roles and away from the sciences for fear that women would lose their femininity and as a way for men to maintain their masculinity (Trecker, 1974). As well, women's natural mental 'inferiority' and physical weakness underlined many arguments in opposing excessive work and imposing limitations on women. Women who failed to follow these regulations were warned of potential ill health and infertility. At a time when the 'Woman Question' was introduced, male professionals attempted to preserve female roles by reinforcing the importance of being a wife and mother. This preservation of female roles and subordination was often reinforced through biology, as exemplified through Clarke's writings. Clarke and Hall attempted to "measure the differences that are assumed to be there, rather than to examine whether or not the differences actually exist" (Lowe, 1982, p.100). Their assumptions of female inferiority 
highlight Tuana's second category of ignorance, we do not even know that we do not know, where Hall and Clarke failed to recognize their internal bias because of societal and cultural beliefs that obscured them. Victorian theories, such as the variability hypothesis and the growing scientific literature that posited women's inferiority to men resulted in androcentric biases towards women's bodies. This is also evidenced in the scientific writings of Herbert Spencer, Charles Darwin, Henry Maudsley, Hermann von Helmholtz and Alexander Bain, which Clarke drew upon to support the idea that women and men had different natural traits. Additionally, Clarke believed social roles for women and men were also rooted in biology. This Victorian doctrine of separate spheres reinforced the belief that men were more naturally assertive and women were more passive (Shields, 2007). With the shift to the late 19 th and 20th century, women began questioning and confronting the Victorian doctrine of separate spheres and biologically based theories. Among these women were many early social scientists (see Rosenberg, 1982).

Despite the substantial support for Clarke and Hall's arguments which discouraged women from seeking higher education, many feminists protested and sought to disprove their theories. This was highlighted in the many newspaper articles that challenged theories of female inferiority. These feminists argued there was insufficient scientific evidence to prove their arguments that women were not hindered by their biology, being perpetually ill during menstruation or physically ill from being educated (Bittel, 2009). The scientific studies that Clarke and Hall used to support their arguments were eventually deemed as lacking scientific rigour. Figures such as psychologist Leta 
Stetter Hollingworth, activist Julia Howe and physicians Clelia Mosher and Mary Putnam Jacobi, and their arguments against Clarke and Hall will be further explored in Chapter 4. 
Chapter 4: Feminist Responses to Clarke, Hall and Female Invalidism

Despite the lack of solid empirical evidence, the ideas set forth by male physicians and psychologists in late 19th and early 20th century America were largely accepted. Medical and scientific practitioners who claimed their analysis of the Woman Question was completely objective were in reality greatly influenced by societal needs and nonscientific ideas (Trecker, 1974). Women began to challenge many of these scientific practitioners and their hypotheses, the majority of whom were male and appeared hostile to changing the status quo of male-female relationships and gender dynamics (Bullough \& Vough 1973, Minton, 2000). This was especially true for the subject of menstruation where many male physicians supported arguments that had no scientific basis, or then wrote findings contrary to the facts they did find (Bullough \& Vough, 1973).

This chapter will focus on several key women who advocated for women's higher education during the 19th and 20th century by debunking medical and psychological theories that argued for the harmful effects of higher education on women's bodies. These women include physicians Mary Putnam Jacobi (1842-1906) and Clelia Duel Mosher (1863-1940), feminist activist Julia Ward Howe (1819-1910) and psychologist Leta Stetter Hollingworth (1886-1939). Their tenacity and perseverance for women's causes greatly impacted Victorian-era medicine that attempted to use science to portray women and men as physical opposites and reinforce female subordination. Science became an essential tool for these women, helping them argue for greater equality by debunking previous claims of female inferiority. This sentiment was expressed by Antoinette Blackwell, the first woman ordained as a minister in the United States who declared 
women must turn ""to the most rigid scientific methods of investigation" to look for a final and authoritative decision as to woman's legitimate nature and functions" (1875, p.229-231). The relationship between science and feminism became a fruitful partnership that enabled women to challenge male scientific dogma and Victorian gender conventions. I will be further exploring their arguments and scientific findings against female inferiority, gender roles, and menstrual invalidism in this chapter. Applying Tuana's epistemology of ignorance will provide a greater understanding of how feminists were positioned by male scientists as 'non knowers'.

\section{Feminism and Medicine: Mary Putnam Jacobi and Clelia Duel Mosher}

Advocates and feminists contested the views of female inferiority which were widespread throughout North America. Challenges to arguments of female inferiority were addressed initially by female physician Mary Putnam Jacobi and later by others including Clelia Mosher. Jacobi, who spearheaded the fight against Clarke, was a physician from New York. Her determination and willpower led her to obtain three medical degrees during her life. Her first degree was awarded to her in 1863 from New York College of Pharmacy, followed by an M.D. in 1864 from the Female Medical College of Pennsylvania in Philadelphia. However, Jacobi was dissatisfied with her education in America and pursued a second M.D. in France at the Ecole de Medecine in Paris. She was the first woman accepted to the Ecole de Medecine and received her M.D. with high honors in 1871. Jacobi devoted her medical career to defining herself as a woman of science by rejecting medical and gender conventions of the 19 th century (Bittel, 2005). She was a vocal supporter of women's rights and expressed her medical 
views in journals, women's organizations and the women's rights leadership (Bittel, 2009). Her legacy as an activist and physician is highlighted by several books and over 120 articles that she published including Mental Action and Physical Health (1874), Shall Women Practice Medicine? (1882) and Women in Medicine (1891).

Jacobi's 1877 essay was one of the first writings to debunk the idea of menstrual debilitation. In her award winning essay, "Do Women Require Mental and Bodily Rest during Menstruation?" Jacobi addressed negative portrayals of menstruation as being pathological, dangerous, crippling to women and linked to crime (1877) (For further analysis of the historical link between menstruation and crime see Chapter 2). However, her main objective was to rebut Clarke's and other physicians' claims that women needed rest during menstruation. She supported her argument by initially providing cultural examples of female labour including women in France who worked in cotton, linen, silk and wool factories. In 1851 Paris, Jacobi cited that 112,189 women were employed in needle-work. Within Great Britain in 1864, 747,261 women worked in the industrial establishments (Jacobi, 1877, p.18). Additionally, in 1870 United States, 1,594,783 women were listed in the American census as part of the paid industry (Jacobi, 1877, p.18). Jacobi included these statistics to highlight the fact that woman of different races and ages were involved in manual labour during the 19th century without requiring rest during menstruation.

Jacobi set out to study the claim made by physicians that a relationship existed between physical and mental labor and deterioration of health for women through a preliminary survey. This comprehensive survey included information regarding what age 
a woman had started school, hereditary history, health before the age of 13 , number of hours studying per day, number of hours exercising per day, occupation, hours of work, first menses, and pain and necessity of rest during menstruation, among other measures. In addition to the survey, Jacobi also performed experiments to further understand the physiology of menstruation. Results from the experiments included statistics, tables and sphygmographic graphs of pulse rates which supported the high stability of women's strength and health during periods of menstruation.

Based on her analysis, Jacobi argued that mental and physical labor did not harm women's reproductive health (Jacobi, 1876). In fact, she claimed that women were healthier when they were educated and physically and mentally active (Bittel, 2009). Therefore, she stated there was no necessity for physical or mental rest for women during menstruation if women have normal nutritional health (Jacobi, 1877). Women's nutritional health was based upon Jacobi's idea that women experienced rhythmic waves of nutrition. Nutritive material was expelled during menstruation when it was not needed for reproduction (Vertinsky, 1990). The only exceptions Jacobi made to bodily rest included women who could become unwell due to menstruation and would therefore be unsuited to perform such activities as obstetrical practice (Vertinsky, 1990). Other exceptions included women who suffered from weakened nerves, either inherited or congenital. For these women, she advised rest during any time of the month, not only during periods of menstruation. Aside from these individuals, it was social limitations, Jacobi argued, not biology that impacted and constrained women. However, science and society were tightly interwoven during the 19th century. Victorian-era physicians used 
biological differences as foundations for societal and gender differences. This is highlighted by scientists who attempted to explain the 'Woman Question' by emphasizing sexual differences between men and women such as women's innate maternal and nurturing abilities that predetermined their natural roles as mothers and wives. Scientific explanations of maternal instinct were based upon the idea that lower mental processes of perception and emotion were more prominent in women's brains. These mental processes were believed to "prove the existence of distinct, innate, universal maternal sentiments" (Shields, 1984, p.258). These sexual differences were often justified through biological theories such as Darwin and Spencer and used to reinforce female subordination. Jacobi's study was followed by the work of Clelia Duel Mosher in the early 1900's. Mosher set out to research the implications of menstrual pain which had traditionally been associated with female weakness of the body. Mosher followed in Jacobi's path to scientifically address claims of menstrual disability (Vertinsky, 1990). Aside from Jacobi, Mosher was the only other female physician who systematically studied menstruation since Clarke's claims that women needed rest during their menstrual cycle. Mosher began her studies on menstruation while she was a graduate student at Stanford University and continued this research at John Hopkins Medical School (Rosenberg, 1982). She was among the 20 percent of Stanford female graduates who choose majors in science (Zieff, 2010). She then returned to Stanford University as a medical adviser to female students (Vertinsky, 1990).

Mosher faulted earlier studies on menstruation which she argued were unsystematic or flawed (Rosenberg, 1982). She designed her studies to systemically 
measure college women's development and growth to draw conclusions around female health and strength (Vertinsky, 1990). Mosher was determined to provide accurate results as she stated "the need for truth with regard to women's physical limitations has become imperative" (1923, p.17). Her studies examined 400 women and 3,350 menstrual cycles while recording respiration rates, blood pressure and blood count (Rosenberg, 1982). Her extensive study also involved longitudinal interviews that she conducted herself and she kept records of monthly private journals that each woman kept throughout the study. Her studies on the menstruation of college women, which spanned from the period of 1890 to 1920 , revealed an association between menstrual difficulties and women's dress, specifically corsets and petticoats (Mosher, 1911). Tight corsets and heavy petticoat skirts were popular in the 1890's, however this clothing restricted breathing and physical activity and caused deformities of the female body. Mosher argued that this resulted in prolonged menstrual flow and disturbances of organs for girls from a young age:

At puberty girls are put into corsets, tight bands, and heavy, unsupported skirts which interfere with the respiratory movements, lessening the action of the diaphragm, rendering the abdominal muscles flabby and inefficient, in some cases changing the type of respiration from abdominal to costal. Thus arise conditions which promote excessive abdominal and pelvic congestion. This in turn changes the physiological periodic congestion of the normal menstrual flow into a chronic congestion which, if not pathological and the beginning of inflammatory processes, certainly prolongs unduly the menstrual flow. (Mosher, 1911, p.56) 
Mosher recorded the width and height of the dress and waist measurements along with degrees of menstrual pain. Her results revealed a correlation between lighter skirts and larger waists and less menstrual pain. In the 1890's, a woman's average waist size was twenty inches and the average petticoat 13.5 feet around the hem, weighing up to 15 pounds. Women's dress changed during World War I, when shorter and lighter skirts came into style and when the average waist size increased by 40 percent (Bullough \& Vough 1973). This was evidenced in statistics Mosher collected where 64 percent of women between 1915 and 1916 claimed to be free of menstrual pain compared to 19 percent of college women in 1894 (Bullough \& Vough 1973).

Based on her studies, Mosher found that the causes of menstrual disorders to be the result of unsuitable clothing that affected respiration, poor posture and digestive functioning and lack of physical activity (Zieff, 2010). Mosher found that women's performance was also not directly impaired by physiology but that physical suffering may be the result of suggestions by physicians (Vertinsky, 1990). Mosher's first step in changing perceptions of menstrual disability included altering women's mental attitudes towards their bodily functions (Vertinsky, 1990). Negative perceptions were embedded in girls and women, stated Mosher, by male physicians who used the term 'sick time' to refer to menstruation. These 'physical influences' as she described them were directed by male physicians who viewed menstruation as pathological and incapacitating for women (Zieff, 2010). Altering women's and girl's attitudes meant teaching them that menstruation should not be negatively viewed and instead helping them form positive attitudes towards menstruation and menopause. Mosher's published works, Women's 
Physical Freedom and Personal Hygiene for Women exemplified these views of having a positive stance towards menstruation, as well as eating healthy, exercising, and dressing appropriately.

Jacobi and Mosher played important roles in using science to dispel previous notions of female inferiority and constructing more positive perceptions of menstruation for women. They revealed medical studies by men as highly prejudiced and at fault of conducting "bad science" (Bittel, 2009). Emphasizing fitness and health for women and focusing more on honoring the female reproductive cycle, Jacobi and Mosher set a new precedent for how women's health was viewed in the 19th century (Vertinsky, 1990). Their use of science shed light on women's abilities to become educated, work in professions outside of the domestic home, and be involved in political activities (Bittel, 2009). However, women who practiced medicine were still strongly linked to the private sphere up until the 18th century. Even when caring for patients, many female physicians did not have the same status as their male counterparts but were instead viewed as skilled amateurs (Morantz-Sanchez, 1985). Although this perspective changed in the 19th century, women entering the medical sphere were seen as unable to subdue natural feminine tendencies such as sympathy which was required to perform medicine (Morantz-Sanchex, 1985). Additionally, Clarke's claims that women required one week of rest due to menstruation brought into question whether female physicians could be depended upon in medical emergencies. This enabled Clarke and Hall among other male professionals to position female physicians as 'non knowers' since they were morally and biologically unsuited to work as medical practitioners. This exemplifies Tuana's fifth 
category of ignorance, ignorance produced by the construction of epistemically

disadvantaged identities where studies by female physicians were often ignored by male practitioners. This ignorance of female physicians and their research perpetuated the menstrual invalidism hypothesis throughout the 19th century and continued to the 20th century which will be analyzed in chapter 5 .

Feminist Activism: Julia Ward Howe's Response to Clarke

Julia Ward Howe, an American social activist and poet, was the president of the American Woman Suffrage Association and New England Women's Club as well as the editor of the Woman's Journal which lobbied for human rights and women's suffrage (Bell \& Offren, 1983). She became involved in social reforms such as abolition, education and prison reform. Despite her husband forbidding Howe to work outside the home, her determination and outspoken views led her to become one of America's most prominent female writers and social reformers of the 19th century (Ziegler, 2003).

Howe became critical of Clarke's arguments when he gave a guest lecture at the New England Women's Club in 1872. The club had invited Clarke on the pretense that he would be speaking of women's higher education, to which, he proclaimed women had a right. However, the speech soon turned sour when Clarke spoke of different methods girls and women needed in order to account for their physiology (Zschoche, 1989). Howe fumed over Clarke's remarks on female frailty and wrote a critical response to Clarke's book Sex in Education to refute claims that educating women caused them to become invalids. Howe's (1874) book Sex and Education: A Reply to Dr. E.H. Clarke's "Sex in 
Education" highlighted several problems with Clarke's hypothesis including his misogynous stance towards women:

Much in Dr. Clarke's treatment of his subject is objectionable. We are left in doubt whether his book was written for men or for women, and we conclude that his method of statement is not good for either. Much of his remarking upon sex is justly offensive, and his statements concerning those single women of culture whom he terms agenes would scarcely be endured in any household in which these single saints bear the burthens of all the others, and lead lives divinely wedded to duty. (Howe, 1874, p.29-30)

Howe's critique of Clarke was one of the first feminist responses to his work Sex and Education. Howe collected testimonies from numerous women's colleges and coeducational universities such as Vassar, Antioch, Michigan, Lombard and Oberlin who attested to the fact that female students did not suffer from ill health as a result of studying. Her book also contained responses from notable feminist figures including Horace Mann, Caroline Dall and Elizabeth Phelps who disputed the supposed association between education and harm to women's reproductive health. She stated on behalf of other feminists that "despite Dr. Clarke's prominent position in this community, we do not feel compelled to regard him as the supreme author on the subjects of which he treats" (Howe, 1874, p.8). Instead, Howe provided other arguments as to why women suffered from possible debilitating effects of menstruation. She pointed instead to the powerful influence of climate on American women (Vertinsky, 1990). Like Engelmann and Mosher, Howe also argued that women's clothes restricted and impeded women's bodies. 
The corset and heavy skirts worn by women prevented them from strengthening their muscles as well as participating in athletic sports (Howe, 1874).

Howe's outspoken and bold demeanor led her to challenge and defy gender conventions of Victorian society. Her women's suffrage work was a response to by her husband who attempted to restrict her to traditional female roles of a submissive wife and dutiful mother. However, Howe sought independence by using her writing to gain an authoritative voice and advocate for women's rights (Ziegler, 2003).

Although Howe was not a trained scientist, she recognized the value of science in elevating her arguments. She critiqued Clarke's use of 'science' in arguing that education affected women's periodicity which she stated "cannot be admitted without more evidence than Dr. Clarke has thus far given us" (p.19). Howe joined Jacobi, Mosher and Hollingworth in condemning the androcentric biases that were present in Clarke's arguments. Science and the authority it held, argued Howe (1874), was used to obscure biases.

It is claimed by admiring critics, in regard to Dr. Clarke's book, that "his method is purely scientific." From this I should be inclined to dissent. The method does not seem to me purely scientific, but popular; and not so much popular as 'clinical, that is, as if familiarly addressed by a physician to a circle of students or patients, among whom the personal authority or popularity of the teacher might be relied upon to fill some gaps in the argument. The purely scientific method waives all such personal prestige. (p.34) 
Howe also specifically critiqued Clarke's case studies in his book Sex and Education. Clarke's use of seven case studies to show how women's physical health was harmed by education was, Howe argued, not representative enough to make generalizations. Additionally, Howe pointed out that two of the women in the case studies, one a clerk and the other an actress, were not educational examples. Howe accused Clarke of not providing a satisfactory basis of facts. She argued that unbiased methods, such as the presentation of statistics on the education of boys and girls would provide better scientific proof. Howe (1874) also critiqued Clarke of "direct unfairness by the omission" of certain information to strengthen his arguments and emphasizing aspects of other studies to provide proof for his arguments (p.37). Howe provided the example of Clarke deliberately ignoring facts around women's health in higher education in such works as the Woman's Journal.

Clarke displayed Tuana's fourth category, willful ignorance by deliberately choosing to ignore studies, writings, and facts that challenged his theory. Many of these facts were produced by feminists. This was pointed out by Howe who voiced her concern over the unbiased scientific methods that Clarke claimed to use in reinforcing his arguments. Clarke as a male physician however held a position of privilege in society with his views on female education reinforced by the male medical community. Yet, this did not dismay Howe who was one of the first feminists to challenge Clarke's work Sex in Education.

Psychologist Leta Stetter Hollingworth: Functional Periodicity and the Variability Hypothesis 
Mosher's research on menstruation greatly supported psychologist Leta Hollingworth's own research on female periodicity as discussed earlier. Hollingworth continued Jacobi and Mosher's efforts in depathologizing menstruation through empirical experiments to prove women's intellectual and physical capabilities. Born in 1886 on a farm in Nebraska, Hollingworth was ambitious in attaining higher education. She completed her undergraduate degree at the University of Nebraska and earned her MA in educational psychology from Columbia University in 1913 (Held, 2010). Hollingworth was an adamant proponent of women's rights and voiced her support of women who had "abilities and aspirations other than those represented by reproduction and manual work" (Hollingworth, 1927, p.17). During her graduate work, she began questioning and critically investigating why women were deemed inferior to men (Benjamin, 1975). However, Hollingworth found no scientific data that supported the claims of renowned psychologists like G. Stanley Hall and Edward Thorndike. This set in motion Hollingworth's determination to conduct her own empirical studies on women's supposed inferiority.

Hollingworth addressed claims of women's inferiority by studying beliefs in menstrual invalidism. This research was conducted for her doctoral dissertation, Functional periodicity: An Experimental Study of the Mental and Motor Abilities of Women during Menstruation (1914), at Columbia University. During her research, she found most medical studies on women were conducted by male physicians (Benjamin, 1975). She critiqued the authority that male scientists held over the subject matter and 
argued that beliefs surrounding the female uterus as disturbing normal functioning in women was a result of bias by male physicians:

It should be obvious to the least critical mind that normal women do not come under the care and observation of physicians. To investigate the matter experimentally has been somewhat difficult, because until recently all investigators were men, and the taboo put upon the phenomenon by men and women alike rendered it a more or less unapproachable subject for experiment by men who were not physicians. (Hollingworth, 1914, p.95)

Normal and healthy women, stated Hollingworth, were not typically under the care of physicians and instead physicians were generalizing their results upon women who were physically and mentally ill and then extending these results to all women (Bullough \& Vough 1973). Hollingworth (1914) took it upon herself to conduct her own psychological studies on menstruation from a female perspective through experiments to test the proposed association between intellect and menstruation. Six women and two male controls were participants in the study and were tested daily on perceptual, motor and mental ability tasks for three months. These tests including tapping, colour naming and identifying opposites. In addition, three of the women's progress in learning to type was recorded over the three months. Hollingworth's study revealed no difference in performance or ability of females during any phase of the menstrual cycle and provided little support for the widely accepted scientific claims of female inferiority. Mosher's findings that periodic incapacity was the result of poor habits instead of womanhood also reinforced Hollingworth's conclusions (Rosenberg, 1982). 
Hollingworth also addressed the variability hypothesis which reinforced women's subordination and which G. Stanley Hall endorsed. The variability hypothesis, proposed by Johann Meckel in the early 19th century, stated that women had greater variability than men. This variability was argued to contribute to women's inferiority. However, with the introduction of evolutionary theory by Charles Darwin a half century later, greater variation became associated with males as it became known as an evolutionary advantageous trait and helped promote intellectual progress. This was supported by the idea that more extremes existed in male intelligence including a higher number of "feeble minded" males along with a greater proportion of "geniuses" (Benjamin, 1975). Although Hollingworth was not a contemporary of Hall's, their lives overlapped. The psychological theory of the variability hypothesis advocated by Hall was prominent during his lifetime and continued to be influential later when Hollingworth addressed it.

Hollingworth (1916) critiqued the variability hypothesis and referred to it as "armchair dogma" and lacking any scientific evidence or demonstration. Aside from psychologist Karl Pearson, Hollingworth was the only other scientist to empirically study the variability hypothesis and publish her results (Benjamin, 1975). Hollingworth began questioning the validity of the variability hypothesis when she became employed at the Clearing House for Mental Defectives. She administered Binet intelligence tests at the Clearing House until she completed her Ph.D and became employed as chief of psychology at Bellevue Hospital (Shields, 1975). During her clinical work, Hollingworth found a higher degree of 'imbecile' boys referred to her than girls (Rosenberg, 1982). However, Hollingworth noted that the high proportion of 'retarded' males in the clinic 
were under the age of 16 . She began to suspect social influences were the cause as more boys came into conflict with the law due to their competitive behavior and were more likely to be referred to psychologists by the court (Shields, 1975). On the other hand, women's less competitive and more dependent behaviour resulted in them entering institutions at an older age when they were unable to self-support (Rosenberg, 1982).

Deciding to investigate the variability hypothesis further, Hollingworth worked with Helen Montague to study the birth weight and height of 2,000 neonates at the New York Infirmary for Women and Children. She decided to study infants as she reasoned they were free from environmental conditions that could account for variability differences (Benjamin, 1975). Her results concluded that there was no difference in variation between male and female infants (Montague \& Hollingworth, 1914). From these studies, Hollingworth argued that the social sciences needed to abandon biological theories which argued the causes of female non achievement and instead objectively examine impediments to women's success (Shields, 1975). She encouraged other women to follow in her footsteps by challenging androcentric assumptions and advised them to "investigate these matters experimentally, now that the opportunity for training and research is open to them. Thus, in time, may be written a psychology of women based on truth, not on opinion; on precise, not on anecdotal evidence; on accurate data rather than on remnants of magic". (Hollingworth, 1914, p.99).

The variability hypothesis was significantly more difficult for feminists like Hollingworth to counter than physiological arguments such as Clarke's. While it was physically possible to demonstrate how women bodies were not being negatively affected 
by education, it proved to be more challenging to show women's minds were equal to men (Russet, 1989). The variability hypothesis entered into the psychological testing movement which was largely male-dominated at its inception and reinforced present scientific and societal ideas of female inferiority. As long as "scientists associated the average with the unprogressive, and the feminine with the average, women were not like to be taken seriously as leaders, as thinkers, or indeed as participants in the majestic forward movement of the human race" (Russet, 1989, p.98). Just as female physicians such as Jacobi and Mosher were not viewed as equals to male physicians, Hollingworth as a female scientist appears to have been similarly disregarded. This highlights a continuing theme of ignorance produced by the construction of epistemically disadvantaged identities. In this fifth category of Tuana's taxonomy, individuals who were deemed to be 'non knowers' were ignored. Female scientists including Hollingworth were given this label and judged as producing knowledge that was not credible. Hall also labelled psychologists who did not share his view of women as 'feminists' as against him, and quickly dismissed their ideas (Diehl, 1986). Psychology marginalized women during a time when Hall and other male scientists warned about the feminization of society (Minton, 2000). For women psychologists, including Hollingworth, to become accepted meant emulating the practices that male psychologists revered, such as empiricism (Minton, 2000). Hollingworth used scientific empiricism to her advantage to reveal the unscientific nature of theories such as the variability hypothesis and the androcentric biases present in psychology.

A New Definition of Femininity: The New Woman 
The increasing number of women entering the workplace and gaining higher education by the beginning of the 20th century led to a re-evaluation of separate spheres for men and women which had exemplified the Victorian era (Minton, 2000). Changing gender ideals also led to redefinitions of women and men. The 'New Woman' of the 20th century embraced her greater economic independence, political consciousness and public visibility (Smith-Rosenberg, 1985). The ‘New Man’ however did not view his changing masculinity in the same positive light. New threats to masculinity emerged due to a higher proportion of women entering higher education and the workplace. The increasing admittance and education of women also led to the fear of feminization of academia (Minton, 2000). Colleges such as the University of Chicago started admitting women due to the financial crisis after the American Civil War (Rosenberg, 1982). The growing industrialization in America resulted in a society that was no longer centered around the family. The concept that women who aspired to have careers outside of the home were selfish began to circulate within American society as it took away from their roles as mothers and wives. This idea was argued by psychologist G. Stanley Hall (1905) who stated that women who could overcome their evolutionary destiny of bearing children to instead become educated were the "very apotheosis of selfishness from the standpoint of every biological ethics" (p.633). This was refuted by feminists who argued that industrialization caused women's natural fundamental nature to be expressed (Addams, 1902). Therefore, feminists argued that women's desire to go beyond the domestic sphere was not due to selfish fulfillment. 
As women began to enter the public sphere with white collar jobs, this fear climaxed to the idea that not only would women lose their femininity but men would lose their masculine identities as well (Rosenberg, 1982). This contributed to American society attempting to keep the status quo and reinforcing traditional feminine and masculine roles for men and women. Supporters of keeping the status quo argued that "woman was caged not by man but by her own physiological nature" (Hollingworth, 1927, p.17).

Hall who was against co-education and adamantly attempted to preserve Victorian ideals of womanhood faced new threats as women began to infiltrate the field of psychology. Female psychologists, such as Leta Hollingworth, began challenging and voicing their concerns over psychology's and medicine's androcentric biases. Declarations by male scientists of female inferiority were typically without scientific evidence which Hollingworth labelled as "folk-lore and folk-ethics rather than science" (1916, p.277). Additionally, she argued that men who made these claims failed to provide any evidence of methods to which they arrived at their conclusions (Lowie \& Hollingworth, 1916). Assumptions about women were no longer freely accepted but were disputed, challenged, and systematically tested.

\section{Summary}

The Victorian era represented a period where most female physicians accepted and supported Victorian decorum for women which was strongly sanctioned by male physicians (Vertinsky, 1990). This endorsement by male and female physicians such as emphasizing women's biological maternal abilities reinforced separate gender spheres 
and sexual polarity (Rosenberg, 1982). Despite women being allowed to enter the medical profession, a female medical career only proved successful when they conformed to traditional femininities and conventional male medical practice and thought (Vertinsky, 1990). Physicians Mary Jacobi and Clelia Mosher proved some exceptions to this tenet. Their feminist stances tackled embedded Victorian societal beliefs of female invalidism while promoting women's physical capabilities. Jacobi highly endorsed the education of women and promoted women entering medicine as she believed it would have a greater impact on the lives of American women. For Jacobi, science was essential for female advancement and women suffrage. It was through medicine and science that women could be proven to be physically fit and capable (Bittel, 2005).

Similarly, psychologist Leta Hollingworth utilized and merged science with political feminist activism to demonstrate women's full capability. Her research on functional periodicity and the variability hypothesis brought new light to commonly held assumptions of female inferiority. Her efforts were hailed by feminists "as the much needed scientific pillar of their cause" (Shields, 1975, p.855). Her efforts to reveal the biases of male scientists and medical practitioners were paralleled with Julia Ward Howe who critiqued Clarke's misogynous statements and unsupported claims on women's ill health due to higher education.

Despite the achievements of feminists and scientists in 19th and early 20th century America, the menstrual invalidism and female inferiority arguments endured into the 20th century. These arguments took new forms, but echoed familiar themes. New disorders, such as premenstrual syndrome (PMS) and premenstrual disphoric disorder (PMDD), 
emerged to pathologize female physiology. Women's bodies became medicalized and monitored with new technology that attempted to validate sexual differences between women and men. Furthermore, new studies continued to be conducted to test women's intellectual capabilities during menstruation while ignoring previous empirical studies conducted by Hollingworth, Jacobi and Mosher who had disproven such arguments. This ignorance of empirical evidence against female inferiority and menstrual invalidism has led to the continuation and perseverance of these arguments against women since the 19th century. Tuana (2008) argues this ignorance is linked to issues of silencing and authority and intersects with systems of oppression. This is evidenced by both Hall and Clarke who ascribed to intellectual ignorance of evidence that contradicted their beliefs of menstrual invalidism. A common thread throughout this chapter was Tuana's fifth category of ignorance, ignorance produced by the construction of epistemically disadvantaged identities. This ignorance was used by Hall and Clarke in positioning feminists who challenged their claims as 'non knowers'.

The resurgence of theories around female inferiority and menstrual invalidism will be further explored in chapter 5. The feminist responses to the resurgence of menstrual invalidism theories will also be explored. Studies by Georgene Seward and Barbara Bernstein on the menstrual cycle, Mary Brown Parlee's work on women's perceptions of PMS and PMDD, and the appearance of menstrual suppression to represent the new woman of the 20th century and second wave feminism, will be examined. Finally, in the conclusion to this chapter I will provide an overview of how ignorance has played a central role in the history of female inferiority since the 19th century. 
Chapter 5: Mid-20th Century to Modern Day Interpretations of the Menstrual Invalidism Hypothesis

Howe, Jacobi, Mosher and Hollingworth utilized different strategies in their critique of Clarke and Hall. Howe supported her arguments through personal testimonies and invocation of expert opinions. For Jacobi, Mosher and Hollingworth, science was essential for female advancement and women suffrage. It was through medicine and science that women were proven to be physically fit and capable. They used science to dispel previous notions of female inferiority and to construct more positive perceptions of menstruation for women. Medical studies by men, they argued, were highly biased and they found their male colleagues at fault for conducting "bad science". The use of feminist empiricism by Howe, Jacobi, Mosher and Hollingworth shed light on women's abilities to become educated and work in professions outside of the domestic home.

However, despite the achievements of feminists and scientists in 19th and early 20th century America, the menstrual invalidism and female inferiority arguments persisted into the 20th century. These arguments took new forms, but echoed familiar themes. New entities, such as premenstrual tension, premenstrual syndrome (PMS) and premenstrual disphoric disorder (PMDD), emerged to further pathologize female physiology. Women's bodies and experiences were subjected to increasing attention and control from the medical establishment (see Held \& Rutherford, 2011, Brodsky, 2008, Metzl, 2003). Additionally, further studies during the 20th century were conducted on the effects of menstruation on intelligence and physical labour despite previous findings in the 19th century disproving such claims. 
This chapter will further explore the status and forms of the menstrual handicap argument from the mid-20th century to today. World War II brought significant changes to American society including a female workforce that challenged the menstrual handicap hypothesis and shifted gender roles (Meyerowitz, 1994). This cultivated a stronger female voice that propelled women into gaining further equality outside the domestic home. From there I will be exploring second wave feminism and the feminist health movements starting in the 1960's which became concerned with the medical establishment and women's reproductive health. Women were encouraged to challenge the appropriation of their bodies by experts and to consider their subjective experiences as valid and part of a larger collective experience of femaleness. This goal was also supported by third wave feminism starting in the 1990's which confronted a growing pharmaceutical and feminine hygiene industry that framed menstruation as shameful, dirty and an annoyance. The introduction of birth control pills and long term menstrual suppression also raised concerns of feminists. Conversely, menstrual suppression resulted in some women feeling greater agency and empowerment. Yet the continuation of menstrual invalidism highlights the critical issue of dismissal where women's voices and scientific evidence were ignored. This chapter will be framed by applying Nancy Tuana's (2006) taxonomy of ignorance to the persistence of the menstrual invalidism debate. I will be arguing that the "menstrual invalidism" debates of earlier in the century continued but took new forms that exerted even greater cultural authority over women's bodies.

WWII, Menstrual Invalidism and the Female Workforce 
The entrance of America into World War II in 1941 brought about significant changes in American society. The enlistment of men in the war as soldiers led to a void in factories that produced war supplies. Between 1940 and 1945 in America, the male work force decreased by almost 9 million (Goldin \& Olivetti, 2013). Women were soon recruited to fill these positions that were once strictly exclusive to men. Women's 'menstrual handicaps' were used as justifications to prevent women from performing physical labour in the 19th century were discarded and replaced with propaganda campaigns such as 'Rosie the Riveter' to encourage women to enter the work force and fight the war. The female work force which stood around 14 million in 1940 increased by more than 7 million female workers (Goldin \& Olivetti, 2013). However, after the war ended in 1945 women were forced to leave their factory jobs and were expected to submissively return to the domestic home.

Psychologist Georgene Seward (1902-1992) began examining women's supposed biological handicaps during WWII. Women's increased involvement in the female workforce led Seward to evaluate their 'menstrual handicaps' and the crucial issue of women's role in postwar society. Seward, born in 1902 in Washington, D.C., earned her PhD from Columbia University in social and clinical psychology (Stansfeld, 1993). She began teaching at Columbia University in 1930 before obtaining teaching positions at Simmons University and University of Southern California. Her research examined reproductive functioning and the effects of hormones on behaviour. Seward's involvement in this research led to her study in 1944 on menstrual handicaps in which she argued that there was no reliable experimental evidence that women's productivity was 
hampered by menstruation. In fact, Seward (1944) argued that the interpretations of past experiments were biased by negative cultural norms surrounding menstruation which resulted in a "code of menstrual invalidism". Seward supported her findings with Jacobi's (1877) conclusions that menstrual pathology was due to societal influences including poor conditions in women's employment and faulty physical education of women. Seward's analysis of previous studies on women's productivity during menstruation also revealed highly variable results and cross cultural differences (Rutherford \& Granek, 2010). Seward (1944) remarked:

although for centuries women have been exploited as cheap labor, society has continued to assume a paternalistic attitude toward them, emphasizing their "need" for special protection. These protective devices actually have "protected" only economic inequalities between the sexes, justified on the assumption of biological inequalities. (p.93)

Seward (1944) noted that only when social mores on menstrual handicaps shifted could women be liberated from a "code of menstrual handicaps" and enable them "confidently to assume their places beside men in the work of the world" (p. 99). This shift on menstrual handicaps required a restructuring of sex roles for men and women, argued Seward. A continuation of economic equality which was witnessed during WWII was pertinent to greater equality of the sexes in the postwar era (Seward, 1946). Prior to WWII, where many women remained within the home, women in the postwar era, noted Seward (1946), could no longer "fit comfortably into the relative isolation of the conventional domestic role" as the "emerging dual role of woman as worker-mother will 
demand extensive readjustments in the social roles of both men and women" (p. 247). Additionally, Seward recognized the importance of individual differences which she argued outweighed sex differences. She suggested that women and men could have equal opportunities if individual differences were prioritized over sex differences. Shifting sex roles would not only benefit women, noted Seward, but she believed men who learned 'feminine' traits would be of greater benefit to society. Just as women were trained to be loving mothers, men could be taught the same traits and fulfill a greater responsibility of child rearing and household tasks within the home. These responsibilities stated Seward needed to be implemented in coeducational institutions where girls and boys were both trained for parenthood as part of their curriculum. Seward's perception of education significantly differed from 19th century psychologist's Hall and Clarke's views which supported separate educational spheres for girls and boys.

Despite previous studies conducted in the 19th century by Jacobi, Mosher and Hollingworth and emerging research in the 20th century by psychologist Seward that disproved menstrual invalidism, studies continued to be performed on menstrual handicaps. With the increasing involvement of women in the public sphere, specifically jobs that required physical labour, studies were conducted that tested the psychological and physical effects of menstruation. Psychological and medical studies began to be conducted on the health of women working in industries that required physical labour. A study in 1943 was conducted by a group of physicians including chairman of the American Medical Association's Committee on the Health of Women in Industry, H. Close Hesseltine, who examined the effects of employment on the gynecologic and 
obstetric health of women (Hesseltine et al., 1943). This report for the Council on Industrial Health recommended including restrooms in industries where women could rest during menstruation and illness. The report also suggested adequate supervision of female workers by supervisors who had experience with 'female problems'. Guidelines for female workers also included instructing women not to lift more than 35 pounds and not exceed a maximum of 48 work hours per week (Hesseltine et al., 1943). While the report acknowledged that many women did not suffer maladies from menstruation, it stated that changes in altitude or climate and positions of responsibilities that could cause worry or tension would result in menstrual distress. Physician H.A. Vonachen (1944) similarly voiced concerns about women's menstrual disabilities and as well as other limitations which he believed could affect work productivity:

One should regard women with consideration of the physical and emotional limitations of the sex, remembering that the female must be considered as three fourths of a man physically. I feel that each job should be studied from the standpoint of monotony, fatigue, lifting, lifting aids, lighting and rest periods. Perhaps the most important consideration is the physical examination (preemployment) with careful attention being paid to the all-important previous medical history of the employee, particularly that portion which deals with female disorders and menstrual history. (Burnell, 1944, p.687)

Despite these medical reports suggesting women's limited abilities, women pushed ahead their right to serve in other professions including the military during WWII. However, women faced continued discrimination as expressed by Major L.W. McIntosh who stated 
that women possessed a "psychological handicap which renders her abnormal, unstable, etc., at certain times" (Treadwell, 1954, p.5). After considerable debate, congress approved the Women's Army Auxiliary Corps (WACC) in 1941 which later was renamed the Women's Army Corps (WAC) in 1943 (Vostral, 2008). By 1943, the Women's Auxiliary Ferrying Squadron (WAF) and the Women Airforce Service Pilots (WASP) where women served as flight instructors, transported supplies, performed flying tests, and participated in gunnery practice were approved. As part of the rules, women were forbidden from flying "one day before the beginning of the menstrual period to two days after it" (Treadwell, 1954, p.614). This rule reflected the widespread belief that menstruating women were susceptible to fainting while flying which could result in fatal crashes, yet this was based more upon myth than fact (Vostral, 2008). This highlights another attempt at constructing ignorance around menstruation and female ability. A report by physician Raymond S. Holtz in 1941, Should Women Fly during the Menstrual Period, concluded that menstruation was a normal physiological process that did not threaten women's ability to fly. The only exceptions Holtz made to his statement were women who suffered from abnormally painful menstrual cycles or those who had endocrine problems. However, the question of whether menstruation debilitated female pilots continued to be investigated and tested. An official report titled Medical Consideration of WASPS (1945) examined such concerns of whether menstruation affected coordination, reaction time and concentration of female pilots. Contrary to previous beliefs, women performed better during the 10 days surrounding their period. Not only was the report able to confirm that flying accidents were unrelated to 
menstruation, it was revealed that some of female instructors in the study had fewer missed days than their male counterparts. Overall, the report concluded that "menstruation, in properly selected women, is not a handicap to flying dependable performance of duty" (1945, p.51).

Aside from questions surrounding women's flying capability, women in the army were also required to admit themselves to the hospital when suffering from menstrual cramps. However, many women concealed their cramps as being admitted to the hospital required rest for 2 to 3 days at which point their menstrual cycles were finished. A record of women's visits to the hospital were recorded and followed them to each assignment with repeat admittance to the hospital as grounds for being diagnosed with a history of menstrual disorder and being dismissed from the army (Vostral, 2008). By concealing their experiences of menstruation women resisted the ignorance that was being perpetuated in the military towards female abilities. The surveillance of women's menstrual cycles by army physicians may highlight a shift towards greater medicalization and medically diagnosed menstrual disorders such as Premenstrual Syndrome (PMS) which was first introduced in the 1950's.

The period of WWII in America highlights a point in history where knowledge of menstrual invalidism was either ignored or emphasized depending on whether it was advantageous to dominant groups. Prior to 1940, many women were restricted to the domestic home based on beliefs that physical labour and higher education were damaging to female reproduction organs. As discussed in chapter 3, this was advocated by Clarke and Hall in the 19th century who argued that menstruation defined 'womanhood' where 
women were predestined to solely become mothers and wives. Clarke and Hall represented institutions of medicine and psychology which performed willful ignorance of studies that disproved menstrual invalidism. Tuana (2006) describes this ignorance as "a willful embrace of ignorance that infects those who are in positions of privilege" and "a belief we know to be false but insist on repeating" (p.11). In this case, medicine and psychology represented these positions of privilege which continued to produce ignorance into the 20th century. This resulted in further oppression of women by restricting their access to the public sphere.

Tuana's fifth category of ignorance, ignorance produced by the construction of epistemically disadvantaged identities, where knowledge constructed by individuals or groups who are deemed as 'non knowers' is ignored can also be applied. Similar to feminists in the 19th century, Georgene Seward was constructed as a 'non knower' by medical and psychological institutions who ignored her research and continued to publish work that argued menstrual disabilities. Similarly, Raymond Holtz's study which denounced menstrual invalidism was ignored by the military, another privileged institution. Holtz's study, which stated that menstruation did not affect a woman's ability to fly an aircraft was judged by the American military to not be credible. The military labeled Holtz's study as untrustworthy and commissioned their own report, as the official one.

In applying Tuana's epistemology of ignorance to the events of WWII, a phenomenon that does not fit into her framework is the incongruency between the recruitment of women into the workforce and the support of menstrual invalidism. An 
example will make the incongruency explicit. With America entering the war in 1941, women were recruited to fill positions in factories and industries that were previously restricted to men. Propaganda campaigns, such as Rosie the Riveter, promoted a new image of women as strong and capable of performing physically demanding jobs. Yet, questions surrounding women's menstrual disabilities and how they affected their productivity persisted and resulted in numerous studies including those conducted by physicians H. C. Hesseltine and H.A. Vonachen at this same time. These studies were ignored by the American government in their recruitment of women to fill factory positions. This phenomena presents an interesting paradox that existed during WWII around women's biological handicaps and women entering the public sphere.

\section{Postwar: Medicalization of Menstruation}

After WWII, menstrual symptoms were viewed as not only detrimental to women but as an illness that needed further medical intervention. This 'medicalization' of menstruation led to the pathologization of a normal bodily change that women experience. Sociologist Zola Irving was instrumental in understanding medicalization in the 1970's which he described as "making medicine and the labels 'healthy' and 'ill' relevant to an ever increasing part of human existence" (1972, p.487). Zola argues that medicalization is not an intentional act of oppression but rather it is a 'situation' where we should examine who benefits and how. Medicalization can also act as a form of social control where individuals monitor their bodies through self-surveillance and alter life styles to prevent illness (Foucault, 1997). Sociologist Peter Conrad (2007) voices a similar perspective where medicine encroaches further on everyday life where non- 
medical and social problems become redefined as disorders and illness. Conrad argues that medicalization results in social consequences and negative implications such as blame and the creation of stigmas. In a similar vein, some feminists view medicalization as having few positive benefits for women and is used as a form of hegemonic medical domination. Medicalization of menstruation and other female biological processes has been profitable for pharmaceutical companies who market natural bodily functions as medical problems (Riessman, 1983). Some feminists have argued that the pathologizing of menstruation has been yet another way to prevent women from seeking employment outside the home (Ussher, 2011). The medicalization of menstruation represents the continuity of menstrual invalidism. Further pathologizing a natural bodily function has resulted in multiple diagnoses (such as premenstrual tension, premenstrual syndrome and premenstrual dysphoric disorder) that are used to mark women's bodies as problematic. By taking these new forms, the medical and psychiatric professions can exert even greater cultural authority over women's bodies in the 20th century.

The symptoms of menstruation were formally identified as a medical issue in 1931 when they were described as 'premenstrual tension' (PMT). This later became renamed 'premenstrual syndrome' (PMS) in 1953 by British endocrinologist Katharina Dalton who felt the term 'tension' was too narrow in describing the multiple components of menstrual symptoms. The renaming of 'tension' to 'syndrome' highlighted an increasing medicalization of menstruation. In the 1950's and 1960's, symptoms of PMS were believed to be so familiar and clear to the observing physician that a lack of standardization of PMS symptoms existed (Herschberg \& Creff, 1955). When PMS 
symptoms were defined, an emphasis was placed on the somatic symptoms compared to emotional symptoms. Although symptoms were identified, the root of PMS was uncertain. Theories of oestrogen excess as the cause of PMS first emerged in American gynaecologist Robert Frank's seminal article in 1931 on premenstrual tension. Extreme attempts to 'cure' women of symptoms involved sterilization by X-ray and hysterectomies (Frank, 1931, Greene, 1954). Other recommendations by Frank and American medical journals included taking diuretic substances which were believed to expel excess hormones. However, the theories of oestrogen excess were soon invalidated and replaced with hormonal or somatic theories by the end of the 1950's (Knappen \& Weisz, 2008). A new theory emerged in the 1950's by British physician Katharina Dalton who argued PMS was a deficiency of progesterone. She advised a hormone replacement therapy to resolve PMS. Although her rationale for progesterone therapy led to it becaming a common treatment in Britain, Dalton's views were not widely accepted among American researchers. It wasn't until the 1980's that progesterone therapy became adopted in the United States (Knappen \& Weisz, 2008).

PMS first appeared in the American psychiatric classification manual, the Diagnostic and Statistical Manual of Mental Disorders in 1987 in Appendix B for further study ( $3^{\text {rd }}$ ed.; DSM-III; American Psychiatric Association, 1980). By inclusion in the $D S M$, PMS transitioned from a medical condition to a psychiatric condition. PMS is defined in the DSM-III (1980) $3^{\text {rd }}$ ed., text revised as disabling symptoms of sadness, irritability, mood swings, fatigue, food cravings and need for emotional closure. However, when the next edition of the DSM was published, PMS was removed. A new 
disorder titled Premenstrual Dysphoric Disorder (PMDD) was included and listed under Mood Disorders beneath the subheading of Depressive Disorders $\left(4^{\text {th }}\right.$ ed.; DSM-IV; American Psychiatric Association, 1994). PMDD is defined in the DSM-IV (1994) $4^{\text {th }}$ ed. as a more severe form of PMS and includes symptoms of depressed mood or sadness, feelings of being 'on edge', frequent tearfulness, persistent irritability, headaches, fatigue, sensations of "bloating", tightness of clothing, binge eating or craving certain foods and change in appetite among others. Five or more of the symptoms as stated in the DSM IV must be present during the last week of the luteal phase in order for PMDD to be diagnosed. With the inclusion of the different categories of diagnosis for menstrual disorders in the DSM, the ignorance of menstruation as a natural bodily process has become more formalized. Physicians were further positioned as 'experts' by the fact that they are given the power to diagnose.

Throughout the 20th century, PMT and PMS were associated with negative social traits including disobedience, poor study habits and running away from home which were believed to be caused by menstruation in girls (Fausto-Sterling 1985). Medical surveillance and control over women began infiltrating other domains of society including penal control. Menstrual cycles and criminal behaviour began to be associated from late 19th century with reports of increasing criminal behaviour by women during phases of the menstrual cycle occurring since the 20th century (Horney, 1978). In a presidential address to the American Association of Obstetricians, Gynecologists, and Abdominal Surgeons in 1945, W.R. Cooke stated that 84 percent of all violent crimes committed by women were during the premenstrual and early menstrual phases of the 
cycle (Horney, 1978). In 1953, Oleck suggested that prosecutors and defense attorneys had the right to investigate the possible connection of premenstrual tension in every case that a female was accused of committing a crime. Additionally, Oleck (1953) proposed the idea that premenstrual tension should legally pass as an insanity defense. A court case in 1991 was the first court case in America that accepted PMS as an explanation of a women's irritable and hostile behaviour when she was pulled over for drunk driving (Solomon, 1995). In 1978, PMS was described by some physicians as the "world's commonest disease" with claims of 80 percent to 100 percent of women experiencing it (Dalton, 1978, p.206). In 2000, it was estimated that approximately 75 percent of women in the United States experienced symptoms of PMS and between 3 percent and 8 percent of women in this group having symptoms to qualify for PMDD (Steiner \& Born, 2000).

Recommendations to treat symptoms of PMS and PMDD included serotonin reuptake inhibitors (SSRIs) including marked drugs of Prozac, Sarafem and Zoloft (Steiner \& Born, 2000). The first six months after SSRI's were approved by the FDA for treating symptoms of PMDD, 2.5 million prescriptions were written (Ussher, 2011). Despite the approval by FDA, it has been inconclusive what causes PMDD. Some speculations include an imbalance of serotonin which can affect monthly hormones (Ussher, 2011). Constructing menstruation as a problem has led to a consumer market of solutions such as feminine hygiene products and pharmaceutical drugs (Kissling, 2006). This presents profitability as another dimension of willful ignorance. There's an outcome of profitability through the promotion of ignorance; we must remain ignorant of the fact 
that there's no scientific evidence that the disorders/problems exist in order for these markets to exist.

The medicalization of menstruation through the creation of disorders such as PMT, PMS and PMDD reveals an emphasis by the medical community on an illness and disease model which stresses biological causes as more significant than socio-cultural influences (Knaapen \& Weisz 2008). From a biological perspective menstruation was also constructed as pathological despite a lack of research on the testosterone hormone in the female body (Fausto-Sterling 1985). This lack of research is due to testosterone being viewed as a male hormone and hence "normal." It could therefore not contribute to perceived abnormalities in mood changes from menstruation (Fausto-Sterling 1985). This has led to the menstrual symptoms experienced by some women being labelled as abnormal and pathological. Ignorance of research on 'masculine' hormones such as testosterone in the female body as well as socio-cultural influences highlights Tuana's second category of ignorance, we do not even know that we do not know, where current beliefs, interests and theories obscure certain topics. This ignorance further genderizes the diagnosis as menstrual disorders become solely associated with female hormones.

Tuana's other perspective on epistemology of ignorance, they do not want us to know, applies to the consumer market for menstrual 'problems'. Tuana describes this ignorance as "knowledge is rendered secret because of national security or because of business interests" for reasons of profits $(2006$, p.9). This includes withholding information about the health implications of products for the sole reason of making a profit. Kissling (2006) reported that in 2000, the FDA approved the first drug treatment, 
Sarafem, for PMDD symptoms. At this point Prozac was already being prescribed by physicians for women who suffered from PMS. After being on the market for 6 months, 8 million dollars' worth of prescriptions of Sarafem had been sold, the equivalent of 202,000 written prescriptions. However, women who were prescribed Sarafem, which is chemically identical to Prozac, may not have been aware of the severe side effects including tics, withdrawal symptoms, Parkinson's-like conditions or even producing suicidal reactions (Kissling, 2006). Ironically, the listed side effects of Sarafem appear on lists of PMS symptoms. Pharmaceutical companies' ignorance of the severity of side effects has resulted in numerous lawsuits and more than 40,000 reports sent to the FDA of experiencing adverse effects (Levine, 2011). Despite these claims, Sarafem remains on the market, revealing an ignorance of women's concerns by the FDA for the safety of the pharmaceutical drug.

Other birth control pills, such as Yaz and Yasmin which are produced by pharmaceutical company Bayer, have raised similar concerns. Between March 2006 and March 2009, Bayer was accused of concealing dangerous side effects from women including heart attacks, blood clots and pulmonary embolisms (Pearson, 2009). In 2008, Yas and Yasmin were top selling drugs for Bayer that brought in 1.8 billion dollars of sales. However, in 2009 over 300 lawsuits were filed against Bayer by women suffering side effects from Yas and Yasmin, some of whom were taking these birth control pills to treat symptoms of PMS. Bayer attempted to keep women ignorant of the dangerous side effects, many of which were the result of an ingredient called drospiernone which studies have linked to blood clots, heart attacks, strokes and pulmonary embolisms. In an attempt 
to promote Yas and Yasmin and increase their profits, Bayer concealed and minimized many of the risks in their advertising campaigns.

The category of ignorance produced by the construction of epistemically disadvantaged identities is also relevant here. When the FDA and pharmaceutical companies such as Bayer ignored women's experiences of their side effects, they positioned these women as 'non knowers'. Female psychologists including Georgene Seward and feminists in the 19th century were similarly constructed as 'non knowers' by medical institutions. The lack of action by the FDA and the refusal of Bayer to address these harmful side effects was prominent in discrediting women's experiences. This created a further hierarchy between women as 'non knowers' and medical institutions and corporations as experts.

Second Wave Feminism and The Women's Health Movement

Female disorders such as PMS were challenged by second wave feminists who addressed issues of sexuality in addition to those related to the family, reproduction, the workplace and inequalities in the workplace. Forerunner to the Second Wave feminist movement, Simone de Beauvoir (1952), addressed the notion that women were the 'second sex' by challenging the idea that male bodies were the norm. Beauvoir, a female French philosopher, was instrumental in advancing women's rights. After a trip to the United States in 1947, Beauvoir wrote a critical work entitled, L'Amérique au jour de jour (America Day by Day), on the social issues, racism and class inequalities that were present. In 1949, Beauvoir published Le Deuxième Sexe (The Second Sex) which became a classic piece of feminist literature. In The Second Sex, Beauvoir argued that the status of 
women was rooted in existentialist philosophy that posits humans do not have a fixed essence or nature. This was embodied by Beauvoir's famous line that "one is not born, but rather becomes, a woman" (1952, p.301). This represented the notion that gender was not only socially constructed but that becoming a gender whether feminine or masculine involves not only submitting to but creating a cultural situation (Kissling, 2006).

Betty Friedan, a feminist, writer and woman's rights activist also challenged gender norms in her book The Feminine Mystique (1963) and sparked the second wave feminist movement. Friedan (1963) argued in The Feminine Mystique that women who remained within the home restricted and limited their talents and potential. Her book challenged the nuclear family by arguing that women who remained in traditional gender roles as wives and mothers were not always happy (Friedan 1963).

Along with challenging gender norms, the feminist health movements starting in the 1960's also became concerned with the medical establishment and women's reproductive health (Morgen 2002). The Civil rights movement and a demand for greater equality ignited a new wave of feminist activism (Kline, 2010). Feminists became increasingly concerned with medical schools and the knowledge espoused by such institutions. For example, the pathologizing of menstruation and other female functions led to constant surveillance of the female body by physicians (Vertinsky 1994). This surveillance prompted feminists to encourage women to understand their bodies themselves without the intervention and control of male physicians (Rogers 1990). Feminists argued that as long as female bodies were subjected to male medical authority they would not be able to achieve full equality (Kline, 2010). The book Our Bodies, 
Ourselves was a landmark publication that promoted the idea that women should undertake to understand their own bodies (Boston Women's Health Book Collective 1971). This work was ground breaking in that it challenged the historical myths constructed by patriarchal experts about women and their bodies. Women were encouraged to challenge the appropriation of their bodies by experts and to consider their subjective experiences as valid and part of a larger collective experience of femaleness (Murphy, 2012). This work encouraged women to return to a more holistic health perspective and a more collective view of health. Along with consciousness raising for women, self-health remedies such as herbal treatments during the women's movement were offered to women as alternatives to professional medicine. This enabled women to choose remedies based on personal decisions that suited their menstrual problems. Yet, framing these remedies as solutions continued to root menstruation as illness that can present problems (Birke \& Best, 1982).

Many feminist psychologists and psychiatrists as well as feminist activists in the 1970's challenged PMS as a disorder as there existed numerous scientific weaknesses in the research being conducted (Knaapen \& Weisz 2008). This included an inability to find the physiological markers of PMS and a lack of standardization of the symptoms (Knaapen \& Weisz 2008). American psychologist Rudolf Moos (1968) designed the Menstrual Distress Questionnaire (MDQ) in an effort to standardize PMS symptoms and to make it more objective. However, feminist psychologists and organizations including Division 35 and The Society for Menstrual Cycle Research criticized the research being conducted that assumed women's behaviour and psyche were determined by their 
hormones (Taylor 2006). The claim that PMS may be hormonal gave rise to the argument that women should be denied important responsibilities outside of the home as changes in her hormones were unpredictable causing them to make irrational decisions (Rodin, 1992). This argument replicated ideologies from 19th century that claimed "domesticity and mothering are the normal attributes of female biology and that deviations from this normal trajectory result in emotional disturbances -insomnia, depression and migraine" (Turner, 1984, p.38). As well, many of the studies described women in pathological and negatives ways such as being labeled 'neurotic' while menstruating (Golub 1976).

Simone de Beauvoir (1952) noted that PMS provided a way for women to express emotions like anger that were not consistent with ideals of femininity. Beauvoir's sentiments were echoed by psychologist Mary Brown Parlee (1982) who stressed the importance that culture and gender norms played in women's experiences of menstrual symptoms. Parlee noted that a "woman's psychological response to the physiological changes associated with her menstrual cycle may also be shaped or modified by cultural practices which attach values to menstruation and to femininity" (1973, p.461). Parlee however did not dismiss biological explanations for PMS but instead emphasized the need for both cultural and biological explanations for menstrual experiences. Similar to feminists in the 19th century, Parlee criticized studies on menstrual cycles that were a result of 'bad science'. This included psychological studies on menstrual cycles which made broad assumptions, lacked control groups, and made distinctions between social and physiological factors in interpreting their data (Parlee, 1973). 
Tuana's second category of ignorance, we do not even know that we do not know, is relevant to how menstruation was perceived. In this category of ignorance, we fail to recognize our internal bias or lack of awareness of certain topics because "our current interests, beliefs, and theories obscure them" (Tuana, 2006, p.6). This results in sexist and androcentric biases. As highlighted by Parlee, women's experiences of menstruation were influenced by cultural practices that emphasized negative perceptions. This led to further pathologizing of menstruation and a continuation of menstrual invalidism. Menstruation as a positive experience was a topic mostly ignored by medicine until second wave feminism and the women's health movement. Using women's experiences in works such as Our Bodies, Ourselves helped reveal cultural biases influenced by medicine and male perspectives. Additionally, works such as the menstrual distress questionnaire highlighted a lack of awareness around menstruation as a process that could be beneficial and positive.

\section{Menstruation and Third Wave Feminism}

Constructing menstruation in a positive light is also an objective of third wave feminists, who have criticized the increasing medicalization of women's bodies. Starting in the 1990's and continuing today, third wave feminism advocates for women's agency. Third wave feminism has also attempted to combat the classism, racism and heterosexism with which second-wave feminism became associated (Bodel, 2010). The second wave represented hegemonic feminism by ignoring women's diversity. Our Bodies, Ourselves (1971) has been challenged by third wave feminists who argue the book was part of a "utopian desire for mutual understanding and an "imagined feminist community"” 
(Davis, 2007, p.174). Some feminists also stress that feminist perspectives are not "universally shared nor universally empowering but need to be constantly rearticulated in order to "work" under different historical, social, cultural, and political circumstances" (Davis 2007 p.194).

Continuing from the second wave, third wave feminists have also challenged the $D S M$, the inclusion of PMDD as a disorder, and western cultural perceptions of PMS being an illness. Johnston (1987), Rodin (1992) and Richardson (1995) have argued that the diverse range and disagreements about definitions of PMS confirms that the disorder is a cultural and ideological construct. Some feminists even suggest that PMS has been constructed to benefit pharmaceutical companies by increasing their profits through doctors who prescribe specific medications (Knaapen \& Weisz 2008). Feminist psychologists have also rejected PMDD as a disease and have voiced that the disorder subjugates women and medicalizes a normal biological process (Chrisler \& Levy 1990, Caplan 1995, Chrisler \& Caplan 2002, Ussher 2003). Some feminist psychologists including Caplan et al. (1992) argue that the introduction of disorders such as PMS and PMDD are created to shape and dominate the behavior of women. This has resulted in over 327 treatments for treating symptoms of PMS since its inception however many lack clinical evidence of their efficacy (Kissling, 2006). Treatments for PMDD continue to surface despite there being "no known etiology for PMDD and no empirical evidence that it exists" (Kissling, 2006, p.58). This position has also been voiced by the Society for Menstrual Cycle Research who are opposed to the inclusion of PMDD in the DSM. 
Third wave feminists have begun to look at the social determinants of PMS instead of supposed biological causes. Research has indicated that women with symptoms of PMS or PMDD are more likely than other women to have stressful lives including mistreatment at work or domestic abuse (Kissling, 2006). Stress in women's lives is emphasized by Ussher (2005) who argues that premenstrual distress is often connected to pressures for women to be nurturers of others, and to be the good wife and mother. Ussher states that these societal expectations and cultural constructions of femininity are central in women's experiences of premenstrual distress, which is then positioned as a disorder by physicians. Feminists have vocalized their concerns over physicians who treat these women with antidepressants which emphasizes the problems as being individual and psychological rather than as social issues (Chrisler \& Caplan, 2002). This ignorance of societal issues by physicians highlights Tuana's second category of ignorance, we do not even know that we do not know, where we fail to recognize our internal bias or lack of awareness of certain topics because "our current interests, beliefs, and theories obscure them" (Tuana, 2006, p.6). Medicine and psychology have focused on the treatment of individuals, which has resulted in societal issues being positioned as biomedical conditions (Ussher, 2005). This internalization of illness has led to physicians and psychologists who do not investigate how the state of one's health is inseparable from the social environment one is a part of. Although feminist research has brought awareness of the ignorance around societal issues that may influence the diagnoses of PMS and PMDD, physicians and psychiatrists still treat these disorders as internal issues by prescribing medication. Tuana (2006) argues that awareness of ignorance results in either 
pursuing what is unknown or simply continuing to ignore as a result of not caring. In this case, institutions of medicine and psychology have continued the production of ignorance by disregarding social influences and further legitimizing medical management over women's bodies.

Some feminists, as a way to distance themselves from identifying PMS as a disorder refer to premenstrual symptoms as premenstrual changes (Russell, 1995). This is part of a promotion by women health activists in adopting a positive view of menstruation. For example, The Menstrual Joy Questionnaire was developed as a parody of the Menstrual Distress Questionnaire to instead focus on the positive aspects of the menstrual cycle. Items on the questionnaire include experiencing high spirits, creativity, power, affection, sexual desire and euphoria (Chrisler, Johnston, Champagne \& Preston, 1994, Nichols, 1995). The questionnaire aimed to shape participants views of menstruation from debilitating and bothersome to joyful and beneficial. In another study, Lee (2002) interviewed two groups of women according to their negative and positive perspectives on menstruation in Health and Sickness: The Meaning of Menstruation and Premenstrual Syndrome in Women's Lives. Her findings revealed that those women who held positive attitudes were more likely to reevaluate negative cultural ideas about menstruation and understand how change was an integral part to menstruation. Women in this group also rejected medical labels of PMS that pathologize a normal and biological female process. This study shows that more attention needs to be placed on women's subjective knowledge of menstruation, which can be a powerful tool in revoking negative concepts of menstruation (Lee 2002). However these positive premenstrual changes are 
rarely presented in the literature as they do not fit into the medical model of menstruation as an illness or disease (Chrisler \& Caplan, 2002, Birke \& Best, 1982). These negative cultural constructions of menstruation were similarly challenged by second wave feminists including Mary Brown Parlee and the work Our Bodies, Ourselves by using women's embodied experiences to acknowledge the positive aspects of menstruation. Tuana's second category of ignorance, we do not even know that we do not know, is extended to this example which reveals the continued ignorance by medicine in recognizing the ways menstruation can be viewed positively. This has perpetuated the pathologizing of menstruation.

Themes of concealment and shame around menstruation have infiltrated Western cultural taboos which view menstruation as "dirty, unpleasant, messy and overall a nuisance" (Fingerson 2003, p.94). Menstruation is seen as bothersome and shameful resulting in women taking considerable time to manage and conceal menstruation. Feelings of self-consciousness are also evident in menstruating girls who may view menstruation as a social stigma (Johnston-Robledo et al. 2003). While menstruation is conveyed by cultural norms as messy and bothersome this is in contrast to views of femininity that are linked to gender roles emphasizing cleanliness and freshness (Forbes et al. 2003). Pharmaceutical and feminine hygiene product companies play on these cultural norms of shame, pathology, and control. By perpetuating these notions, companies profit by labeling the female body as 'abnormal'. Perceptions around concealment reside in marketing campaigns for pads and tampons which shame women into hiding any signs of menstruation, making a normal process invisible. Similarly, the 
idea of 'control' over menstruation is used by pharmaceutical companies in promoting birth control pills. The introduction and FDA approval of birth control pills such as Seasonale for menstrual suppression has raised concerns by feminists. For example, Emily Martin cautions women who use Seasonale in reducing the number of monthly periods that "despite the obvious appeal [of menstrual suppression] we must wonder what the price of such fashionable convenience might be" (p.xiv-xvi). Martin (2001) states that women for whom menstruation causes serious problems might welcome the cessation of their periods. But to make all menstruation pathological for all women goes far beyond the bounds of what we know and begins to sound like a scientific replacement for the idea that menstruation is dangerous and polluting. One has to wonder whether the virtual elimination of women's periods might make women's bodies appear more calm, steady, and predictable, in short, less 'troublesome'. (p.xiv-xvi)

However, Martin's sentiments are not voiced by all third wave feminists. The introduction of birth control and menstrual suppression is seen by some feminists as part of women's agency and empowerment. They believe that women should have the choice to eliminate their periods if desired and that feminists who are not supportive of menstrual suppression are burdening women with the stigma and restrictions that menstruation brings (Bodel, 2010). Conversely, many feminists including SMCR, have voiced concerns over long term menstrual suppression as a lifestyle choice. This concern revolves around side effects of hormonal therapies for women which usually do not surface until years later when they are on the market (Bodel, 2010). The unknown 
dangers of long term menstrual suppression pills such as Seasonale highlights Tuana's first category of ignorance, knowing that we do not know, but not caring to know, where knowledge is pursued in the interest of dominant groups. In this case, pharmaceutical companies have ignored feminist's concerns around the potential long term side effects of 'eliminating' a woman's period through menstrual suppression. The lack of long term studies by pharmaceutical companies reveals this issue as unimportant by not conducting further research. As a result, pharmaceutical companies who hold positions of power are part of the production of ignorance around women's bodies.

\section{Summary}

The mid 20th century represented a period when women began entering the public domain in greater numbers. When the United Stated entered WWII in 1941, a burgeoning female workforce was created in traditionally male dominated trades such as factory work. Concerns that pervaded the 19th century, namely that women required rest during physical work, were discarded and replaced by propaganda campaigns such as 'Rosie the Riveter' in 1942 that represented women as strong, proud and physically capable of factory work while they were menstruating. This included drilling, welding, and steelwork among other tasks. Women felt a new sense of empowerment over their bodies in comparison to 19 th century when women were told of their physical limitations. Yet, at the end of WWII in 1945 women were expected to revert back to their positions as housewives or traditionally female roles such as secretaries. Despite a newfound equality that women experienced during WWII, doubts surrounding women's performance during menstruation persisted. In 1931, premenstrual tension became classified as a disorder. 
Menstruation became further medicalized with emerging disorders of PMS and PMDD through the DSM. Surveillance and medical invention by physicians were deemed necessary to control women's hormones that were increasingly becoming associated with poor behavior, crime, psychiatric illnesses, suicides and accidents.

Pharmaceutical companies and physicians promoting hormonal drugs to cure symptoms of PMS ushered in a new era of ignorance in the 20th century creating a further division between women as knowers of their body and physicians as learned experts. Physicians became experts in diagnosing PMS and PMDD despite a lack of scientific evidence of what caused these disorders. Theories around serotonin and progesterone depletion circulated in the medical literature while only speculative. This ignorance of what causes PMS and PMDD however did not prevent FDA approval of hormonal drugs and SSRIs. FDA approval led to lucrative profits for pharmaceutical companies and physicians who prescribed them.

Feminists became concerned with women's ignorance of their own bodies. Male physicians who appropriated expertise of women's bodies were often unchallenged. This was especially disconcerting with the number of women who were prescribed hormonal pills for PMS and PMDD but were ill informed of dangerous side effects. Second wave feminism and the women's health movement challenged women's ignorance of their bodies by creating a new body of knowledge through women's experiences. Women became experts of their bodies by turning ignorance into embodied knowledge. However, the second wave was highly critiqued by third wave feminism of ignoring diversity and 
being hegemonic. Third wave feminists aimed to reverse this ignorance through the representation of women from minority groups.

Throughout the 19th and 20th century, science has been used by dominant groups to maintain privilege within society by exerting control over women and their bodies. Medical science is "rooted in our particular form of social hierarchy and control" where "we do not hear the story, we only hear the "facts," and this is part of what makes science so powerful" (Martin, 1992, p.197). Feminists in the 19th century used the power of science to attempt to dispel the myths of menstrual invalidism and in the process advance feminist politics by dispelling female inferiority and showing that menstruation was not debilitating. Their use of experiments exposed male biases that were present in many scientific studies supporting menstrual disabilities. These studies by male physicians and psychologists were labelled by feminists of being non-objective and confined to the perspectives and interests of the dominant class (Best, 1982, Bodel, 2010, MoantzSanchez, 1985).

However, 20th century feminists utilized different strategies to combat the persistence of menstrual invalidism compared to 19th century feminists. The second and third wave feminists used embodied experiences to create a feminist epistemology that empowered women. Women's experiences of menstruation overpowered and displaced medical discourses that pathologized menstruation. Additionally, self-help health literature by feminists enabled women to take control of their bodies and reposition menstruation as a natural phenomenon. Feminist psychologists identified the positive 
aspects of menstruation to combat the pathologization of menstruation and produce consciousness raising among women.

Science therefore was used by different groups in the 19th and 20th century to elevate their position in society. However, when science was used by feminists, their positions as "non-knowers" resulted in dominant male groups ignoring the knowledge they produced and making them invisible. Additionally, using science as a medium was often inaccessible to women who were not scientists. 20th century feminists instead used embodied knowledge to advance feminist politics. This resulted in greater dissemination and consciousness raising among women and produced feminist movements.

Tuana's epistemology of ignorance is a relevant lens to examine the dimensions of ignorance as presented during 20th century America in regard to menstruation. In this way, epistemologies of ignorance have been operated and maintained over time by menstrual invalidism assuming new forms that reproduce ignorance. Ignorance was produced reflecting societal, economic and medical trends that combined to further entrench the notion of menstrual invalidism. The production of ignorance is kept active through the ongoing construction of new pathologies that further entrench menstrual invalidism. Furthermore, the recent creation and marketing of pharmaceuticals for menstrual suppression infers the idea of disease that must be eradicated.

\section{Conclusion}

I began my discussion of menstrual invalidism by portraying the ways menstruation has been positively and negatively perceived in Western culture since Ancient Greece and Rome. Negative themes of menstruation as polluting, poisonous, and 
dangerous resonated from antiquity to Medieval and Elizabethan England to Early Modern France. These perceptions were often perpetuated by male medical doctors and philosophers to justify their beliefs of female inferiority. Figures such as Aristotle, Pliny the Elder and works including De secreta mulierum demonstrate these perceptions. Positive views of menstruation also existed, but were less ubiquitous. Menstruation symbolised a healthy body and was seen by some as beneficial for pregnancy. Many views of menstruation existed on a spectrum and were reflective of changing historical norms and circumstances. These perspectives revealed menstruation as a complex bodily function informed by scientific agendas and cultural views.

Moving into the main body of my thesis, I explored how negative portrayals of menstruation persisted into 19th and 20th century America. This included the perpetuation of menstrual invalidism from the 19th century to modern day that echoed similar themes but took new forms. The perseverance of menstrual invalidism since the 19th century was partly a result of the efforts of male physicians and psychologists who ignored studies that disproved menstruation as debilitating. These studies were often conducted by feminists whose studies went unacknowledged by physicians and failed to change mainstream psychology (Shields, 1994). Tuana’s (2006) epistemology of ignorance framework was used to examine the "ways in which not knowing is sustained and sometimes even constructed" (p.3). Tuana's epistemology of ignorance provided a deeper understanding of the different relationships between ignorance and those in authority. 
In the 19th century, this ignorance was performed by figures G Stanley Hall, Edward Clarke and the male physicians who continued to cite Clarke's work and produce similar theories around the dangers of higher education for women. However, moving into the 20th century, ignorance of women's voices shifted to a larger scale with the medicalization of menstruation. Ignorance was now performed at an institutional level including by the military, medical and pharmaceutical companies, all resulting in greater surveillance over women's bodies. The medicalization of menstruation through the creation of alleged disorders such as PMT, PMS and PMDD proved to be profitable for pharmaceutical companies and medical doctors who prescribed hormonal drugs. A lack of studies on the effects of hormonal drugs did not prevent physicians from prescribing them to women. Complaints by women of severe side effects were ignored by the FDA allowing pharmaceutical companies to continue a profitable business. This ignorance of women's voices throughout 19th and 20th century was an example of women being rendered as "not knowers" (Code, 1991). Women, who have been epistemically disadvantaged, are constructed as untrustworthy (Shields, 1994). As a result, women in the 19th and 20th century constructed their own feminist epistemologies to "undermine oppressive practices" (Shields, 1994, p.14).

Women in the 19th and 20th century who challenged male medical and psychological institutions by demanding equal opportunity were met with arguments about female biological limitations. These biological theories that stated women were 'naturally' disadvantaged were used by male scientists who wanted to strengthen and preserve dominant economic and political interests (Lowe, 1982). Such theories were 
often given precedence for offering naturalistic explanations for distribution of power in our society (Lowe, 1982). Therefore, science has been used in many ways to exert dominance, reinforce social hierarchies and maintain the status quo (Russett, 1989). Feminists in the 19th century, utilized different strategies in undermining these oppressive acts as compared to 20th century feminists. Psychologists Hollingworth and Seward and physicians Mosher and Jacobi used science to dispel menstrual invalidism. Their scientific experiments revealed the biases present in studies conducted by Clarke and other supporters of menstrual disabilities. Similarly, activist Howe used scientific critique in her arguments against Hall and Clarke. However, while 19th century feminists used science to combat menstrual invalidism, 20th century feminists utilized embodied knowledge to discount medical discourses that pathologized menstruation. Women's experiences were used to create a feminist discourse that portrayed menstruation as a natural process.

Tuana's epistemology of ignorance lent an analytic framework to deconstruct and understand how menstrual invalidism has persevered since the 19th century in America. This perseverance has taken different forms and has been deeply embedded in societal and cultural discourses, often scientific ones, which has ensured the longevity of menstrual invalidism. 


\section{References}

Addams, J. (1902). Democracy and social ethics. Urbana, IL: University of Illinois Press.

American Psychiatric Association. (1987). Diagnostic and statistical manual of mental disorders ( $3^{\text {rd }}$ ed., text rev.). Washington, DC: American Psychiatric Publishing. American Psychiatric Association. (1994). Diagnostic and statistical manual of mental disorders $\left(4^{\text {th }}\right.$ ed.). Washington, DC: American Psychiatric Publishing.

Beauvoir, S.de. (1947). L'Amérique au jour de jour. Paris: Gallimard.

Beauvoir, S.de. (1952). The second sex. Translated by H.M. Parshley. New York, NY: Vintage Books.

Bederman, Gail. (1995). Manliness \& civilization: A cultural history of gender and race in the United States, 1880-1917. Chicago: University of Chicago Press.

Bell, S.G. \& Offren, K.M. (1983). Women, the family and freedom, 1750-1880. Stanford, CA: Stanford University Press.

Benjamin, L.T.Jr. (1975). The pioneering work of Leta Hollingworth in the psychology of women. Nebraska History, 56, 493-505.

Bildhauer, B. (2005). The Secrets of Women (c.1300): A medieval perspective on menstruation. In A. Shail \& G. Howie (Eds.), Menstruation: A cultural history. (pp.65-75). New York, NY: Palgrave Macmillan.

Bildhauer, B. (2006). Medieval blood. Great Britain: Cromwell Press.

Bittel, Carla. (2009). Mary Putnam Jacobi \& the politics of medicine in nineteenthcentury America. United States: The University of North Carolina Press.

Bittel, C. (2005). Science, suffrage and experimentation: Mary Putnam Jacobi and the 
controversy over vivisection in late nineteenth-century America. Bulletin of the History of Medicine, 79(4), 664-694.

Birke, L. \& Best, S. (1982). Changing minds: Women, biology, and the menstrual cycle. In. R. Hubbard, M.S. Henifin, \& B. Fried. (Eds.), Biological woman-the convenient myth: A collection of feminist essays and a comprehensive bibliography (pp.161-184). Cambridge, MA: Schenkman Publishing Company.

Blackwell, A.C. (1908, March 1). Feminization of Boys: Dr. G. Stanley Hall’s Opinions Cause Forth Vigorous Replies from some of the Country's Foremost Women. The New York Tribune, p.10. Retrieved from http://chroniclingamerica.loc.gov/lccn/sn 83030214/1908-03-01/ed-1/seq-32/

Blackwell, A.B. (1875). The sexes throughout nature. New York, NY: G.P. Putnam's Sons.

Bodel, C. (2010). New blood: Third wave feminism and the politics of menstruation. United States: Rutgers University Press.

Bullough, V. \& Voght, M. (1973). Women, menstruation, and nineteenth-century medicine. Bulletin of the History of Medicine, 47(1), 66-82.

Brainiest Woman. (1895, May 5). St. Paul daily globe, p.13. Retrieved from http://chroniclingamerica.loc.gov/lccn/sn90059522/1895-05-05/ed-1/seq-14/

Brodsky, P.L. (2008). Women versus medicine through the ages: The control of childbirth. Jefferson, NC: McFarland.

Brundage, J. A. (1987). Law, sex and Christian society in medieval Europe. Chicago: Chicago University Press. 
Burnell, M.R. (1944). Health maintenance program for women in industry. The Journal of the American Medical Association, 124(11), 683-687.

Burstyn, J.N. (1980). Victorian education and the ideal of womanhood. Totowa, NJ: Barnes \& Noble Books.

Chrisler, J. C., \& Caplan, P. (2002). The strange case of Dr. Jekyll and Ms. Hyde: How PMS became a cultural phenomenon and a psychiatric disorder. Annual Review of Sex Research, 13, 274-306.

Chrisler, J. C., Johnston, I. K., Champagne, N. M. and Preston, K. E. (1994). Menstrual joy: The construct and its consequences. Psychology of Women Quarterly, 18, 375-387.

Clarke, H. E. (1873). Sex in education; A fair chance for the girls. New York, NY: Arno Press Inc.

Clarke, H.E. (1874). The building of a brain. Boston: James R. Osgood \& Company.

Clouston, T.C. (1883). Female education from a medical point of view. Popular Science Monthly, 24, 322-333.

Code, L. (1991). What can she know? Feminist theory and the construction of knowledge. Ithaca, NY: Cornell University Press.

Conrad, P. (2007). The medicalization of society: On the transformation of human conditions into treatable disorders. Balitmore, MD: The John Hopkins University Press.

Crawford, J. (1981). Attitudes to menstruation in Seventeenth-Century England. Past and Present, 91, 47-73. 
Crowder, S. (1766). The female worthies. London: Published for S. Crowder.

Dalton, K. (1978). Once a month: The menstrual syndrome, its causes and consequences. Harvester, London: Fontana Press.

Dalton, K. (1961). Menstruation and crime. British Medical Journal, 2, 1752-1753.

Dalton, K. (1959). Menstruation and acute psychiatric illness. British Medical Journal, 17(1), 148-149.

Darnall, W.E. (1901). The pubescent girl. American Gynecological and Obstetrical Journal, 18, 490.

Davis, K. (2007). The making of our bodies, ourselves: How feminism travels across borders. Durham: Duke University Press.

Delaney, J., Lupton, M.J., \& Toth, E. (1976). The curse: A cultural history of menstruation. Chicago, IL: University of Illinois Press.

Diehl, L.A. (1986). The paradox of G. Stanley Hall: Foe of coeducation and educator of women. American Psychologist, 41(8), 868-878.

Dorr, R.C. (1915, Sept 19). Is Women Biologically Barred from Success? The New York Times, p.15. Retrieved from http://search.proquest.com.ezproxy.library.yorku.ca /hnpnewyorktimes/docview/97714380/FE7FA5E8E6694E41PQ/7?accountid=151 82

Dyke, V.F.W. (1905). Higher education a cause of physical decay in women. Medical Records, 67: 296-298.

Easteal, P.W. (1991). Women and crime: Premenstrual issues. Trends and Issues in Crime and Criminal Justice. 31, 1-8. 
Edgerton, J.A. (1909, June 10). Bismarck Daily Tribune, p.2. Retrieved from http://chroniclingamerica.loc.gov/lccn/sn85042242/1909-06-10/ed-1/seq-2/

Edward Hammond Clarke. (1877-1878, May). Proceedings of the American Academy of Arts and Sciences. p.437-439.

Ehrenreich, B. \& English, D. (1978). For Her Own Good: 150 Years of the Experts' Advice to Women. New York, NY: Anchor/Doubleday.

Ellis, H. (1909). Man and woman: A study of secondary sexual characters (4th ed.). Cambridge, MA: Walter Scott Limited.

Engelmann, G.J. (1890). Causes which imperil the health of the American girl, and the necessity of female hygiene. Medical News (1882-1905) American Periodicals, 57(23), 599 .

Engelmann, G.J. (1900). The American evil of to-day. The influence of modern education on functional development. Transactions, 25, 8-45.

Fausto-Sterling, A. (1985). Myths of gender: Biological theories about women and men. New York: Basic.

Fingerson, L. (2005). “Adolescents' medicalization of menstruation”. Paper presented at the annual meeting of the American Sociological Association, Marriott Hotel, Loews Philadelphia Hotel, Philadelphia, PA Online <APPLICATION/PDF>. 2009-05 25 from http://www.allacademic.com/meta/p20529_index.html

Forbes, G.B., Adams-Curtis, L.E., White, K.B., Holmgren, K.M. (2003). The role of hostile and benevolent sexism in women's and men's perceptions of the menstruating woman. Psychology of Women Quarterly, 27(1), 58-63. 
Freidenfelds, L. (2009). The modern period: Menstruation in twentieth-century America. Baltimore: John Hopkins University Press.

Friedan, B. (1963). The feminine mystique. New York, NY: W.W. Norton.

Gilmore, S. (Ed.). (2008). Feminist coalitions: Historical perspectives on second-wave feminism in the United States. United States: University of Illinois Press.

G. Stanley Hall is Here: The Most Famous Pedagogue of America Visits the Coast. (1898, Dec 25). The San Francisco Call, p.9. Retrieved from http://chroniclingamerica.loc.gov/lccn/sn85066387/1898-12-25/ed-1/seq9/\#date1=1836\&sort=relevance\&rows=20\&words=G+Hall+HALL+STANLEY+ Stanley $\&$ search Type $=$ basic $\&$ sequence $=0 \&$ index $=14 \&$ state $=\&$ date $2=1922 \&$ proxte $\mathrm{xt}=\mathrm{g}+$ stanley + hall $\& \mathrm{y}=0 \& \mathrm{x}=0 \&$ dateFilterType $=$ yearRange $\&$ page $=2$

Goldin, C. \& Olivetti, C. (2013). Shocking labor supply: A reassessment of the World War II on women's labor supply. American Economic Review, 103(3), 257-262.

Goodell, W., Thomas, T.G., Chadwick, J.R., Mitchell, S.W., et al. (1889). Special article: Co-education and the higher education of women. Medical News (1882-1905) American Periodicals, 55(24), 667-679.

Green, M.H. (2005). Flowers, poisons and men: Menstruation in medieval Western Europe. In A. Shail \& G. Howie (Eds.), Menstruation: A cultural history. (pp.5164). New York: Palgrave Macmillan.

Greene, R. (1954). Discussions on the premenstrual syndrome. Proceedings of the Royal Society of Medicine, 48, 337-338.

Hall, G. S. (1905). Adolescence, its psychology and its relations to physiology, 
anthropology, sociology, sex, crime, religion and education. (Vols.1-2). New York, NY: Appleton.

Hall, G. S. (1906). Youth, its education, regimen, and hygiene. New York, NY: Arno Press \& The New York Times.

Hall, G.S. (1908). Feminization of Boys: “A Good Sound Flogging” as a Remedy for Coddling. The New York Tribune. Retrieved from http://chronicling america.loc.gov/lccn/ sn83030214/1908-02-23/ed-1/seq 27/\#date1=1836\&index=2\&rows=20\&words= G+HALL+STANLEY\&searchType=basic $\&$ sequence $=0 \&$ state $=\&$ date2 $=192$ $2 \&$ proxtext $=\mathrm{g}+$ Stanley + hall $\& \mathrm{y}=0 \& \mathrm{x}=0 \&$ dateFilterType $=$ yearRange $\&$ page $=1$

Haller, J.S.Jr. \& Haller, R.M. (1974). The physician and sexuality in Victorian America. Urbana, IL: University of Illinois Press.

Held, L. \& Rutherford, A. (2011). Can't a mother sing the blues? Postpartum depression and the construction of motherhood in late 20th century America. History of Psychology, 15(2), 107-123.

Held, L. (2010). Profile of Leta Hollingworth. In A. Rutherford (ED.), Psychology's Feminist Voices Multimedia Internet Archive. Retrieved from http://www.feministvoices.com/leta- hollingworth/

Hesseltine, H.C.; Burnell, M.; Litzenberg, J. C.; Schauffler, G. C.; Seibels, R. E.; Phaneuf, L. E., and Williams, P. F. (1943). Women in industry; preliminary report of the committee on the health of women in industry of the section on obstetrics and gynecology. Journal of American Medical Association, 121(11), 799-802.

Hiltmann, G. (2005). Menstruation in Aristotle's concept of the person. In A. 
Shail \& G. Howie (Eds.), Menstruation: A cultural history. (pp.25-37). New York: Palgrave Macmillan.

Hindson, B. (2009). Attitudes towards menstruation and menstrual blood in Elizabethan England. Journal of Social History, 43, 89-114.

Hollingworth, L. (1927). The new woman in the making. Current History, 27(1), 15-20. Hollingworth, L. (1914) Functional periodicity: An experimental study of the mental and motor abilities of women during menstruation. Columbia University, United States.

Holtz, R.S. (1941). Should women fly during the menstrual period? Journal of Aviation Medicine, 12, 300-303.

Horney, J. (1978). Menstrual cycles and criminal responsibility. Law and Human Behaviour, 2(1), 25-36.

Houppert, K. (1991). The curse: Confronting the last unmentionable taboo: Menstruation. New York: Farrar, Straus, and Giroux.

Howe, J.H. (1874). Sex and education: A reply to Dr. E. H. Clarke's "sex in education”. Boston: Roberts Brothers.

Hows, A, G. (1885). Health statistics of women college graduates: Report of a special committee of the association of collegiate alumnae: Annie G. Howes chairman; Together with statistical tables collated by the Massachusetts bureau of statistics of labor. Boston: Wright \& Potter Printing Co.

Interesting to Club Women. (1908, July 4). Bismarck Daily Tribune, p.2. Retrieved from http://chroniclingamerica.loc.gov/lccn/sn85042242/1908-07-04/ed-1/seq-2/ 
Jacobi, P.M. (1891). Women in medicine. In Annie Nathan Meyer (Ed.), Women's Work in America. (pp.139-205). New York, NY: Henry Holt.

Jacobi, P.M. (1882). Shall women practice medicine?, North American Review, 134, 5275.

Jacobi, P.M. (1877). The question of rest for women during menstruation. New York: G.P. Putnam's Sons.

Jacobi, P.M. (1874). Mental action and physical health. In Anna C. Brackett (Ed.), The Education of American Girls Considered in a Series of Essays, (pp.255-306). New York, NY: G.P. Putnam's Sons.

Johnston, T.M. (1987). Premenstrual syndrome as a Western culture-specific disorder. Culture, Medicine and Psychiatry, 11(3), 337-356.

Johnston-Robledo, I., Ball, M., Kimberly, L. Zekoll, A. (2003). To bleed or not to bleed: Young women's attitudes toward menstrual suppression. Women \& Health, 38(3), $59-75$.

Katz, D.S. (1999). Shylock's gender: Jewish male menstruation in Early Modern England. The Review of English Studies, 50(200), 440-462.

Kellogg, J.H. (1882). Plain facts for young and old. Burlington, IA: I.F. Segner. Kissling, E.A. (2006). Capitalizing on the curse: The business of menstruation. United States: Riener.

Kline, W. (2010). Bodies of knowledge: Sexuality, reproduction, and women's health in the second wave. United States: The University of Chicago Press.

Knaapen, L. \& Weisz, G. (2008). The biomedical standardization of premenstrual 
syndrome. Studies in History and Philosophy of Biological and Biomedical Sciences, 39, 120-134.

Ladies by the Thousand. (1893, May 17). Rock Island daily Argus, p.1. Retrieved from http://chroniclingamerica.loc.gov/lccn/sn92053945/1893-05-17/ed-1/seq-1/

Laqueur, T. (1990) Making sex: Body and gender from the Greeks to Freud. Cambridge: Harvard University Press.

Lee, S. (2002). Health and Sickness: The meaning of menstruation and premenstrual syndrome in women's lives. Sex Roles, 46(1-2), 25-35.

Lennon, J. (2011). Menstrual blood in Ancient Rome: An unspeakable impurity? Classica et Mediaevalia, 61, 71-87.

Levine, B.E. (2001). Commonsense rebellion: Debunking psychiatry, confronting society. New York, NY: Continuum.

Lewis, T. (1721). The history of Hypatia, a most impudent school-mistress of Alexandria: Murder'd and torn to pieces by the populace, in defence of Saint Cyril and the Alexandrian Clergy. From the aspersions of Mr. Toland. London: Printed for T. Bickerton, at the Crown in Pater-Noster-Row.

Lord, A. (1999). "The Great Arcana of the Deity" Menstruation and menstrual disorders in Eighteenth-Century British medical thought. Bulletin of the History of Medicine. 73(1), 38-63.

Lowie, R.H. \& Hollingworth, L. (1916). Science and feminism. The Scientific Monthly, $3(3), 277-284$

Mandziuk, R.M. (2010). "Ending women's greatest hygienic mistake”: Modernity and the 
mortification of menstruation in Kotex advertising, 1921-1926. Women's Studies Quarterly, 38(3/4), 42-62.

Maudsley, H. (1884). Sex in mind and education. Syracuse, NY: Bardeen.

Mary Putnam Jacobi. (1895, July 28). The Norfolk Virginian, p.8. Retrieved from http://chroniclingamerica.loc.gov/lccn/sn85025715/1895-07-28/ed-1/seq-8/

Martin, E. (2001). The woman in the body: A cultural analysis of reproduction. Boston, MA: Beacon Press Books.

McClive, C. (2005). Menstrual knowledge and medical practice in Early Modern France, c.1555-1761. In A. Shail \& G. Howie (Eds.), Menstruation: A cultural history. (pp.76-89). New York: Palgrave Macmillan.

McClive, C. (2004). Bleeding flowers and waning moons: a history of menstruation in France, c. 1495-1761. (Unpublished doctoral dissertation), United Kingdom: University of Warwick.

Medical considerations of WASPS. (1945). Women's Collection, Texas Woman's University Library.

Meyerowitz, J. (Ed.). (1994). Not June Cleaver: Women and gender in Postwar America, 1945-1960. PA: Temple University Press.

Metzl, J. (2003). Prozac on the couch: Prescribing gender in the era of wonder drugs. Durham, MC: Duke University Press.

Minton, H.L. (2000). Psychology and gender at the turn of the century. American Psychologist, 55(6), 613-615. 
Montague, H., \& Hollingworth, L. S. (1914). The comparative variability of the sexes at birth. American Journal of Sociology, 20, 335-370.

Moos R. H. (1968). The development of the menstrual distress questionnaire. Psychosomatic Med, 30, 853-867.

Morantz-Sanchez, R.M. (1985). Sympathy and science: Women physicians in American science. New York, NY: Oxford University Press.

Mosher, C.D. (1911). Functional periodicity in women and some of the modifying factors. California State Journal of Medicine, 9(2), 55-58.

Mosher, C.D. (1923). Women's physical freedom. New York, NY: The Women's Press. Mulvey-Roberts, M. (2005). Menstrual Misogyny and Taboo: The Medusa, Vampire, and the Female Stigmatic. In A. Shail \& G. Howie (Eds.), Menstruation: A cultural history. (pp.149-161). New York: Palgrave Macmillan.

Murphy, M. (2012). Seizing the means of reproduction: Entanglements of feminism, health, and technoscience. United States: Duke University Press.

O'Grady, K. (2003). The semantics of taboo: Menstrual prohibitions in the Hebrew bible. In K. de Troyer et al. (Eds.), Wholly woman, holy blood: A feminist critique of purity and impurity. (pp.1-28). New York: Trinity Press International.

Oleck, H.L. (1953). Legal aspects of premenstrual tension. International Record of Medicine and G.P. Clinics, 162, 492-501.

Parker, R. (1983). Miasma: Pollution and purification in early Greek religion. Oxford: Clarendon Press.

Parlee, M.B. (1982). New findings: menstrual cycles and behavior. Ms, 11, 126-128. 
Parlee, M.B. (1973). The premenstrual syndrome. Psychological Bulletin, 80(6), 454-465.

Parsons, R.W. (1907). The American girl versus higher education, considered from a medical point of view. New York Medical Journal, 85, 116.

Pearson, S. (2009, October 6). Bayer sued, accused of hiding yaz risk to boost sales. Bloomberg. Retrieved from http://www.bloomberg.com/apps/news?pid= newsarchive\&sid=aSNT6D0_k0Kc

Phenomena of Vision. (1878, Oct 2). The Princeton Union. Retrieved from http://chroniclingamerica.loc.gov/lccn/sn83016758/1878-10-02/ed-1/seq-5/

Potter, W.W. (1891). How should girls be educated? In. The Medical Herald. Vol 10. (301-311). St. Joeseph, MO: The Medical Herald Publishing Company.

Ranke-Heinemann, U. (1990). Eunuchs for the kingdom of heaven: Women, sexuality and the catholic church. New York: Doubleday.

Read, S. (2008). “Thy Righteousness is but a menstrual clout”: Sanitary practices and prejudice in early modern England. Early Modern Women: An Interdisciplinary Journal, 3, 1-25.

Richardson, J.T. (1995). The premenstrual syndrome: A brief history. Social Science \& Medicine, 41(6), 761-767.

Richlin, A. (1992). The garden of Priapus: Sexuality and aggression in Roman humour (Revised ed.). New York: Oxford.

Riessman, C.K. (1983). Women and medicalization: A new perspective. Social Policy, 14(1), 3-18.

Rodin, M. (1987). The social construction of premenstrual syndrome. Social Science 
Medical, 35(1), 49-56.

Rodkey, E. (2010). Profile of Milicent Shinn. In A. Rutherford (Ed.), Psychology's Feminist Voices Multimedia Internet Archive. Retrieved from http://www.feminist voices.com/milicent-shinn/

Rosenberg, R. (1982). Beyond separate spheres; Intellectual roots of modern feminism. New Haven, CT: Yale University Press.

Ross, D. (1972). G. Stanley Hall: The psychologist as prophet. Chicago, IL: University of Chicago Press.

Rothman, S.M. (1978). Woman's proper place: A history of changing ideals and practices, 1870 to the present. New York, NY: Basic Books.

Russell, D. (1995). Women, madness and medicine. Cambridge, MA: Polity Press.

Russet, C.E. (1989). Sexual science: The Victorian construction of womanhood. Cambridge, MA: Harvard University Press.

Rutherford, A. \& Granek, L. (2010). Emergence and development of the psychology of women. In J.C. Chrisler \& D.R. McCreary. (Eds.), Handbook of gender research in psychology, volume 1 (pp.19-42). United States: Springer.

Sargent, S. S. (1993). Georgene H. Seward (1902-1992). American Psychologist, 48(10), 1089.

Schools Effeminized. (1908, Jan 4). The Wenatchee Daily World, p.1. Retrieved from http://chroniclingamerica.loc.gov/lccn/sn86072041/1908-01-04/ed-1/seq- 
1/\#date1=1836\&index=13\&rows=20\&words=G+Hall+Stanley\&searchType=basi c\&sequence $=0 \&$ state $=\&$ date $2=1922 \&$ proxtext $=g+$ stanley + hall $\& y=0 \& x=0 \&$ dateF ilterType=yearRange $\&$ page $=1$

Seward, G.H. (1944). Psychological effects of the menstrual cycle on women workers. Psychological Bulletin, 41(2), 90-102.

Seward, G.H. (1946). Sex and the social order. United States: McGraw-Hill Publications. She has a Logical Mind. (1894, July 20). Bismarck weekly tribune, p. 6. Retrieved from http://chroniclingamerica.loc.gov/lccn/sn85042588/1894-07-20/ed-1/seq-6/

Shields, S. A. (2007). Passionate men, emotional women: Psychology constructs gender difference in the late 19th century. History of Psychology, 10, 92-110.

Shields, S. A. (1994). “Blindsight”: Overcoming mainstream psychology's resistance to feminist theory and research. Psychological Inquiry, 5, 92-96.

Shields, S.A. (1984). “To pet, coddle, and 'do for': Caretaking and the concept of maternal instinct. In. M. Lewin (Ed.), In the shadow of the past: Psychology portrays the sexes. (p.256-273). New York, NY: Columbia University Press.

Shields, S. A. (1982). The variability hypothesis: The history of a biological model of sex differences in intelligence. Signs, 7, 769-797.

Shields, S. A. (1975). Functionalism, Darwinism, and the psychology of women. American Psychologist, 30, 739-754.

Shields, S. A. (1975). Ms. Pilgrim's progress: The contributions of Leta Stetter Hollingworth to the psychology of women. American Psychologist, 30, 852-857.

Shinn, M. W. (1895). The marriage rate of college women. Century Magazine, 50, 946- 
948.

Shuttleworth, S. (1990) Female circulation: Medical discourse and popular advertising in the mid-Victorian era. In M. Jacobus, E. F. Keller \& S. Shuttleworth. (Eds.), Body/politics: Women and the discourses of science. (pp.47-68). London, Great Britain: Routledge.

Smith-Rosenberg, C. (1985). Disorderly conduct: Visions of gender in Victorian America. New York, NY: Knopf.

Solomon, L. (1995). Premenstrual syndrome: The debate surrounding criminal defense. Maryland Law Review, 54(2), 571-600.

Stolberg, M. (2005). Menstruation and sexual difference in Early Modern medicine. In A. Shail \& G. Howie (Eds.), Menstruation: A cultural history. (pp.90-101). New York: Palgrave Macmillan.

Strickland \& Burgess. (Eds.). (1965). Health, growth and heredity: G. Stanley Hall on natural education. New York, NY: Teacher's College Press.

The Building of a Brain. (1875, April 29). Herald and Tribune. Retrieved from http://chroniclingamerica.loc.gov/lccn/sn85033429/1875-04-29/ed-1/seq-2/

The Child by Dr. G. Stanley Hall. (1907, Sept 29). The New York Tribune, p.2. Retrieved from http://chroniclingamerica.loc.gov/lccn/sn83030214/1907-09-29/ed-1/seq26/\#date1=1836\&sort=relevance\&rows=20\&words=G+Hall+Stanley\&searchTyp $\mathrm{e}=$ basic $\&$ sequence $=0 \&$ index $=15 \&$ state $=\&$ date $2=1922 \&$ proxtext $=g+$ stanle $y+$ hall $\& y=0 \& x=0 \&$ dateFilterType $=$ yearRange $\&$ page $=2$

Treadwell, M.E. (1954). United States army in World War II, special studies: The 
women's army corps. Washington, DC: Office of the Chief of Military History, Dept. of the Army.

Trecker, J.L. (1974). Sex, science and education. American Quarterly, 26(4), 352-366.

Tuana, N. (2008). Coming to understand: Orgasm and the epistemology of ignorance. In. R. Proctor \& L. Schiebinger. (Eds.), Agnotology: The making and unmaking of ignorance. (108-145). Stanford, CA: Stanford University Press.

Tuana, N. (2006). The speculum of ignorance: The women's health movement and epistemologies of ignorance. Hypatia, 21(3), 1-19.

Turner, B. (1984). The body and society: Explorations in social theory. Oxford: Blackwell.

Ussher, J.M. (2011). The madness of women. East Sussex: Routledge.

Ussher, J.M. (2005). Managing the Monstrous Feminine: Regulating the Reproductive Body. Florence, KY: Routledge.

Ussher, J. (1989). The psychology of the female body. Great Britain: Routledge.

Verbrugge, M.H. (1988). Able-bodied womanhood: Personal health and social change in Nineteenth-century Boston. New York, NY: Oxford University Press.

Vertinsky, P.A. (1990). The Eternally Wounded Woman: Women, Exercise and Doctors in the late nineteenth Century. England: Manchester University Press.

Vostral, S.L. (2008). Under wraps: A history of menstrual hygiene technology. United States: Lexington Books.

Walling, W.H. (1904). Sexology. Philadelphia: Puritan Publishing Company.

Warde-Fowler, W. (1911). The religious experience of the Roman people from the 
earliest times to the age of Augustus. London: Macmillan and Co.

West, K. (1919, June 1). Julia Ward Howe, Friend of America. New-York Tribune, p.8. Retrieved from http://chroniclingamerica.loc.gov/lccn/sn83030214/1919-0601/ed-1/seq-66/

Wickham, M. (1958). The effects of the menstrual cycle on test performance. British Journal of Psychology, 49(1), 34-41.

Wiesner, M.E. (2000). Women and gender in early modern Europe. (2 $2^{\text {nd }}$ ed.). United States: Cambridge University Press.

Zieff, S.G. (2010). Leading the way in science, medicine and physical training: Female physicians in academia, 1890-1930. The International Journal of the History of Sport, 27(7), 1219-1236.

Ziegler, V.H. (2003). Diva Julia: The public romance and private agony of Julia Ward Howe. Harrisburg, PA: Trinity Press International.

Zola, K. (1972). Medicine as an institution of social control. Sociological Review, 20(4), 487-504.

Zschoche, S. (1989). Dr. Clarke revisited: Science, true womanhood and female collegiate education. History of Education Quarterly, 29(4), 545-569. 